\title{
Fungicide resistance in Cercospora species causing cercospora leaf blight and purple seed stain of soybean in Argentina
}

\author{
Francisco J. Sautua ${ }^{1}$ (D) | Vinson P. Doyle ${ }^{2}$ | Paul P. Price ${ }^{3}$ | Alejandro Porfiri $^{4}$ | \\ Paula Fernandez $^{5,6}$ | Maria M. Scandiani ${ }^{7}$ | Marcelo A. Carmona ${ }^{1}$ (D)
}

${ }^{1}$ Cátedra de Fitopatología, Facultad de Agronomía, Universidad de Buenos Aires, Buenos Aires, Argentina

${ }^{2}$ Department of Plant Pathology and Crop Physiology, LSU AgCenter, Baton Rouge, LA, USA

${ }^{3}$ Macon Ridge Research Station, LSU

AgCenter, Winnsboro, LA, USA

${ }^{4}$ Independent consultant

${ }^{5}$ Consejo Nacional de Investigaciones

Científicas y Técnicas, Ciudad Autónoma de Buenos Aires, Argentina

${ }^{6}$ Instituto de Agrobiotecnología y Biología Molecular (IABIMO) UEDD INTA CONICET, Hurlingham, Argentina

${ }^{7}$ Centro de Referencia de Micología (CEREMIC), Facultad de Ciencias

Bioquímicas y Farmacéuticas, Universidad

Nacional de Rosario, Rosario, Argentina

\section{Correspondence}

Marcelo A. Carmona, Cátedra de

Fitopatología, Facultad de Agronomía,

Universidad de Buenos Aires, Av. San Martín

4453, C.A.B.A, C1417DSE, Argentina.

Email: carmonam@agro.uba.ar

\section{Funding information}

Universidad de Buenos Aires, Grant/Award Number: UBACyT 20020170100147BA; Louisiana State Board of Regents, Grant/ Award Number: LEQSF-2016-19-RD-A-1; BASF Argentina SA

\begin{abstract}
Cercospora species cause cercospora leaf blight (CLB) and purple seed stain (PSS) on soybean. Because there are few resistant soybean varieties available, CLB/PSS management relies heavily upon fungicide applications. Sensitivity of 62 Argentinian Cercospora isolates to demethylation inhibitor (DMI), methyl benzimidazole carbamate $(\mathrm{MBC}$ ), quinone outside inhibitor (Qol), succinate dehydrogenase inhibitor (SDHI) fungicides, and mancozeb was determined in this study. All isolates were sensitive to difenoconazole, epoxiconazole, prothioconazole, tebuconazole, and cyproconazole ( $\mathrm{EC}_{50}$ values ranged from 0.006 to $2.4 \mu \mathrm{g} / \mathrm{ml}$ ). In contrast, $51 \%$ of the tested isolates were sensitive ( $\mathrm{EC}_{50}$ values ranged from 0.003 to $0.2 \mu \mathrm{g} / \mathrm{ml}$ ), and $49 \%$ were highly resistant $\left(\mathrm{EC}_{50}>100 \mu \mathrm{g} / \mathrm{ml}\right)$ to carbendazim. Interestingly, all isolates were completely resistant to azoxystrobin, trifloxystrobin, and pyraclostrobin, and insensitive to boscalid, fluxapyroxad, and pydiflumetofen $\left(\mathrm{EC}_{50}>100 \mu \mathrm{g} / \mathrm{ml}\right)$. The $\mathrm{G} 143 \mathrm{~A}$ mutation was detected in $82 \%$ (53) of the Qol-resistant isolates and the E198A mutation in $97 \%$ (31) of the carbendazim-resistant isolates. No apparent resistance mutations were detected in the succinate dehydrogenase genes (subunits $s d h B, s d h C$, and $s(h D)$. Mancozeb completely inhibited mycelial growth of the isolates evaluated at a concentration of $100 \mu \mathrm{g} / \mathrm{ml}$. All Argentinian Cercospora isolates were sensitive to the DMI fungicides tested, but we report for the first time resistance to Qol and MBC fungicides. Mechanism(s) other than fungicide target-site modification may be responsible for resistance of Cercospora to Qol and MBC fungicides. Moreover, based on our results and on the recent introduction of SDHI fungicides on soybean in Argentina, Cercospora species causing CLB/PSS are insensitive (naturally resistant) to SDHI fungicides. Insensitivity must be confirmed under field conditions.
\end{abstract}

\section{KEYWORDS}

Cercospora spp., DMI, E198A, G143A, Qol, SDHI

\section{1 | INTRODUCTION}

Cercospora leaf blight (CLB) and purple seed stain (PSS), caused by Cercospora kikuchii, are important fungal diseases of soybean (Glycine max) worldwide (Ward et al., 2015). PSS symptoms manifest on infected seed as light to dark-purple discolorations that can cover part or the whole surface of the seed. CLB symptoms in the field appear as a purplish bronze blight in the upper third of the canopy during the reproductive growth stages of soybean (Ward et al., 2015). CLB and PSS are part of the late season soybean disease (LSD) 
complex, which is characterized by latent infections (Carmona et al., 2015).

In Argentina, the average damage caused by LSD to yield is estimated at $10 \%$, but can reach up to $30 \%$ (Carmona et al., 2017a). However, because of the difficulty and complexity of assessing yield and economic losses caused only by CLB and PSS under field conditions, there are still no accurate estimates of yield losses in Argentina. In the USA, the average economic losses due to CLB/PSS across 28 states were estimated at $\$ 77.8$ million per year between 1996 to 2016 (Bandara et al., 2020).

It is thought that $C$. kikuchii was introduced into South America from Asia, most probably Japan, through seed (Imazaki et al., 2006a). This proposed route of introduction is based on amplified fragment length polymorphism analysis of a collection of isolates from Japan and South America (mainly Argentina and some from Brazil). The first molecular and phylogenetic identification of $C$. kikuchii isolated from CLB/PSS symptoms in Argentina came from Groenewald et al. (2013). However, over the past few years additional studies using multilocus phylogenetic analyses of cercosporoid fungi isolated from soybean in Argentina, Brazil, and the USA have confirmed that CLB and PSS are associated with several cryptic species (Soares et al., 2015; Albu et al., 2016a). In South America, C. kikuchii and C. cf. sigesbeckiae have been reported to be associated with these diseases. Recently, C. cf. nicotianae was identified as one of several species in association with CLB in Bolivia (Sautua et al., 2019a), and has been confirmed for the first time to be a causal agent of CLB on soybean (Sautua et al., 2020). However, these studies focused on a limited number of isolates not representative of the major soybean-growing regions in Argentina, one of the largest soybean-producing countries in South America. Therefore, sampling a greater number of isolates from different regions of Argentina to confirm the identity of the CLB/PSS-causing species is critical.

So far, there are no LSD-resistant soybean varieties available, and crop rotation, seed treatment, and fungicide application are the only available control measures to combat these diseases (Carmona et al., 2015). In Argentina, estimates indicate that approximately half of the area planted to soybean annually (on average 17 million hectares) is treated with fungicides at least once per crop season (authors' unpublished data). Mixtures of two or three fungicide active ingredients (a.i.) from demethylation inhibitor (DMI, FRAC Code 3), quinone outside inhibitor (Qol, FRAC Code 11), and succinate dehydrogenase inhibitor (SDHI, FRAC Code 7) mode of action (MoA) groups are commonly used as commercial fungicide formulations sprayed during the reproductive growth stages of soybean (Carmona et al., 2011, 2017a). In Argentina, Qol fungicides in mixtures with DMI fungicides (Qol + DMI) have been applied in soybean cultivation since 2002 (Carmona et al., 2011). In comparison, methyl benzimidazole carbamates (MBC), mainly carbendazim, have been used in soybean crops over the last 30 years as the sole a.i. Lastly, SDHI fungicides were introduced to the market in 2015 as part of a triple mixture Qol + DMI + SDHI (Carmona et al., 2017b).

In Argentina there are no previous studies on fungicide sensitivity of Cercospora isolates causing CLB/PSS, except a preliminary study that determined that one single $C$. kikuchii isolate was sensitive $\left(\mathrm{EC}_{50}<1 \mu \mathrm{g} / \mathrm{ml}\right)$ to four Qol + DMl commercial mixtures (Carmona et al., 2017b). In the USA, Price et al. (2015) reported Qol and MBC resistance in Cercospora isolates from Louisiana. These researchers reported that Qol fungicides were first used in Louisiana in 2000 and CLB-control failures began to appear in 2005, and were generalized from 2012 onwards. Afterwards, Albu et al. (2016b) reported that the G143A mutation in the cytochrome $b$ gene was the cause of Qol-resistance in C. cf. flagellaris isolates from Louisiana. Sautua et al. (2019a) reported that this mutation conferred resistance to azoxystrobin in Bolivia. These are the only reports on mutations that confer resistance to Qol fungicides in this pathosystem. Dixon et al. (2020) reported that mutations F129L and G143A conferred resistance to azoxystrobin in C. nicotianae, the causal agent of frogeye leaf spot of tobacco. Imazaki et al. (2006b) reported on the E198A mutation in the $\beta$-tubulin gene as responsible for the resistance to thiophanate-methyl (MBC fungicide) in C. kikuchii observed in Japan. There are no additional studies on mutations or mechanisms that confer resistance to fungicides in C. kikuchii infecting soybean crops.

Similarly, CLB-control failures have been observed over the last 6 years in many soybean fields throughout Argentina. In these field plots, CLB intensity remained high even after being sprayed with MBC fungicides or Qol + DMI or Qol + DMI + SDHI mixtures. These observations motivated the present study to: (a) collect samples of soybean leaves and seeds displaying CLB and PSS symptoms distributed throughout Argentina and isolate cercosporoid pathogens; (b) determine the identity of the isolates using a multilocus phylogenetic approach; (c) determine the sensitivity or resistance of Cercospora isolates to DMI, MBC, Qol, and SDHI fungicides; and (d) identify the mutations associated with field resistance.

\section{2 | MATERIALS AND METHODS}

\section{1 | Fungal isolates}

Isolates of Cercospora spp. were obtained from soybean leaves and seeds with symptoms sampled from 2014 to 2019 from commercial soybean fields throughout Argentina and Santa Cruz, Bolivia. Samples were taken at random from different fields. Additionally, isolates of Cercospora spp. were obtained from Amaranthus hybridus with symptoms and from symptomless Araujia hortorum leaves sampled in 2019 from Bragado and San Andrés de Giles, Buenos Aires province, respectively. A. hybridus and $A$. hortorum leaves were sampled from soybean fields and adjacent urban areas, respectively, to examine whether these species were alternative hosts for the pathogen, and also to explore their sensitivity to fungicides. The total samples in Argentina were divided into three regions: north-west, centre, and south-east, and within each area, isolates were chosen at random. The north-east (two isolates) and west (three isolates) regions were not included as they were not equally represented. Only one isolate per seed or leaf was selected. Fungal isolation was performed according to the method 
described by Price et al. (2015). Isolates were maintained on potato dextrose agar (PDA; Britania) at $25^{\circ} \mathrm{C}$ with a $16 \mathrm{hr}$ light:8 hr dark cycle and preserved with three different storage methods: (a) in cryovials with sterile water at $4^{\circ} \mathrm{C}$, (b) on PDA slants covered with sterile mineral oil at room temperature, and (c) in $20 \%$ glycerol at $-40^{\circ} \mathrm{C}$. In Argentina, Cercospora isolates had been exposed mainly to carbendazim and Qol + DMI mixtures, whereas in Bolivia they had been exposed to Qol, DMI, SDHI, MBC, and more recently to multisite fungicides such as mancozeb. Thus, for the present study, 62 Argentinian and 3 Bolivian isolates from different locations were chosen to represent surveyed areas equitably (Table S1). Of the total samples from Bolivia, an isolate of each species previously identified (Sautua et al., 2019a) was chosen at random. Thus, in total, the present study included 65 isolates for the in vitro fungicide sensitivity tests and the exploration of mutations that were associated with the observed resistance phenotypes. Of these 65 isolates, a subset of 42 isolates was chosen to perform a phylogenetic analysis to determine the species identity (Table S2).

\section{2 | Pathogenicity tests}

To confirm pathogenicity on soybean, we carried out pathogenicity tests in greenhouse assays with each isolate. The 65 isolates were inoculated onto 11 soybean varieties (DM3810, DM4214, DM4612, DM4615, DM4670, DM4915, NS4309, NS4611, NS4619iPRO, NA5009, and NA5019iPRO) that represented the most common cultivars grown in the Argentinian Pampas region. The methodology was carried out according to Sautua et al. (2020). Conidial suspensions $\left(10^{3}\right.$ conidia/ml) from each isolate grown on soybean leaf decoction agar (Sautua et al., 2020) were sprayed on whole plants at the beginning seed stage (R5 stage; Fehr and Caviness, 1977). Spore suspensions were prepared by collecting spores from 7-day-old colonies in sterile water, with $1 \mathrm{ml}$ Tween $20(0.2 \%)$ added to facilitate the dispersal of conidia. Leaves sprayed with sterile distilled water plus Tween 20 (0.2\%) served as the control. After inoculation, plants were kept in moist chambers for $24 \mathrm{hr}$. Following this initial period, plants were maintained in the greenhouse at $24 \pm 3^{\circ} \mathrm{C}$. The plants were closely observed on a daily basis for the detection of symptoms. This procedure was carried out until physiological maturity. The experiment was repeated twice. After detection of symptoms in inoculated leaves, these were incubated and the pathogen was reisolated. The reisolated isolates were compared with the original isolates to confirm the completion of Koch's postulates.

\section{3 | DNA extraction}

For DNA extraction, liquid cultures of isolates were initiated by placing small pieces of mycelium into $250 \mathrm{ml}$ flasks containing $50 \mathrm{ml} \mathrm{po-}$ tato dextrose broth, prepared according to a standard recipe (U.S.
Food and Drug Administration, 2001). The initial mycelium was carefully scraped with a sterile needle from the aerial mycelia of cultures growing on PDA plates. Liquid cultures were incubated at $24^{\circ} \mathrm{C}$ for 3 days in the dark with constant shaking provided by a standard shaker. After incubation, mycelia were recovered with a strainer and approximately $600 \mathrm{mg}$ transferred to a sterile $1.5 \mathrm{ml}$ microcentrifuge tube. Genomic DNA was extracted following the Dellaporta protocol (Dellaporta et al., 1983). Quantification and quality control of extracted DNA was performed with a NanoDrop spectrophotometer (Thermo Fisher Scientific) and diluted to a working concentration of $12 \mathrm{ng} / \mu \mathrm{l}$.

\section{4 | Isolate identification}

\subsection{1 | actA, cmdA, his3, tef1, and gapdh amplification and sequencing}

Forty-two isolates were chosen to be characterized by sequencing portions of five nuclear loci: actin (actA), calmodulin ( $\mathrm{cmdA}$ ), histone 3 (his3), translation elongation factor 1- $\alpha$ (tef1), and glyceraldehyde-3-phosphate dehydrogenase (gapdh; Table S2), and aligning them with data from 379 other isolates published by Groenewald et al. (2013) and Bakhshi et al. (2018; Table S3, see Section 2.4.2). Fragments of actA, cmdA, his3, tef1, and gapdh genes were amplified from genomic DNA with the primers described in Table 1. The protocols and PCR conditions were those previously described (see references in Table 1). Additional primers were designed using Primer3 v. 4.1.0 (Untergasser et al., 2012) for either improving amplification or sequencing of $\mathrm{cmdA}$ of a few isolates. PCR products were purified using the Wizard PCR and Gel Cleanup System (Promega) and sequencing services were performed by Macrogen Inc. (www.macrogen.com). Sequencing reactions were carried out with the same primers as in the PCR amplifications.

\subsection{2 | Model testing, phylogenetic analysis, and species assignment}

Sequences were edited and contigs assembled in Geneious v. 8.1.3 (https://www.geneious.com). Each locus was aligned using iterative refinement methods implemented in MAFFT v. 7 (Katoh et al., 2019) with the G-INS-I algorithm, a 200 PAM/k $=2$ scoring matrix, gap penalty of 1.53 , and offset of 0.0 . Individual locus alignments were concatenated into a multilocus alignment with data from previous studies. Sequence data of the nuclear ribosomal internal transcribed spacers (nrITS), actA, cmdA, his3, and tef1 published by Groenewald et al. (2013) along with data of actA, cmdA, his3, tef1, and gapdh from Bakhshi et al. (2018) were integrated with the data generated for this study. Septoria provencialis CPC_12226 was included as an out-group. The final alignment lengths and number of parsimony informative characters (PIC) 


\begin{tabular}{|c|c|c|c|c|c|c|c|c|c|c|c|c|c|}
\hline 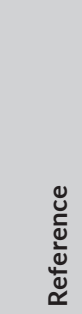 & 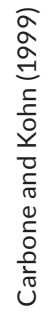 & 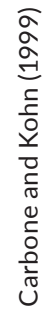 & 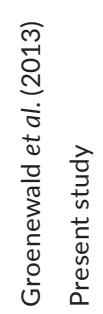 & 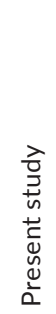 & 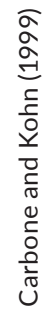 & 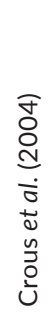 & 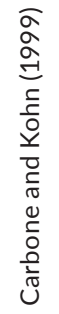 & 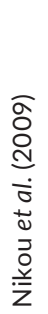 & 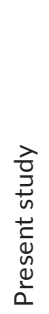 & 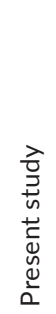 & 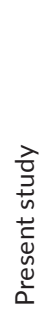 & 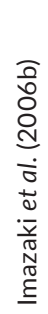 & 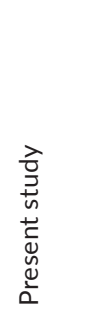 \\
\hline$\dot{\partial}$ & in & $\nabla$ & & & $\nabla$ & $N$ & in & 0 & & & $\nabla$ & & \\
\hline 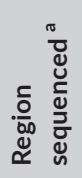 & 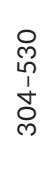 & 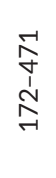 & 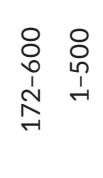 & $\begin{array}{l}\text { o } \\
\text { h } \\
\text { 1 } \\
\text { in }\end{array}$ & 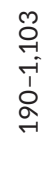 & 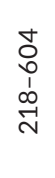 & 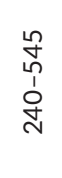 & 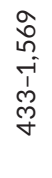 & $\begin{array}{l}0 \\
\text { 足 } \\
\text { i }\end{array}$ & 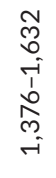 & $\begin{array}{l}\vec{I} \\
\stackrel{1}{0} \\
-i \\
-1\end{array}$ & 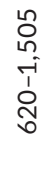 & 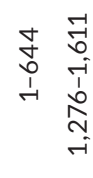 \\
\hline 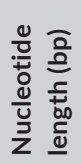 & $\begin{array}{l}\stackrel{0}{\Lambda} \\
\stackrel{n}{\sim}\end{array}$ & 苫 & & & 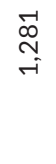 & fơ & $\begin{array}{l}\circ \\
\stackrel{\circ}{\infty} \\
-\end{array}$ & $\begin{array}{l}\text { ్ָ } \\
\text { - } \\
\text { - }\end{array}$ & & & $\begin{array}{l}\vec{\sigma} \\
\stackrel{\overrightarrow{0}}{-}\end{array}$ & & \\
\hline 毫哭 & $\stackrel{n}{\stackrel{n}{m}}$ & $\underset{\sim}{\stackrel{g}{f}}$ & & & $\stackrel{\infty}{m}$ & 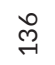 & 多 & 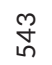 & & & f & & \\
\hline ত & & & $\begin{array}{l}a \\
\dot{j} \\
\infty \\
0 \\
0 \\
0 \\
n\end{array}$ & & & & & & & & & & \\
\hline
\end{tabular}

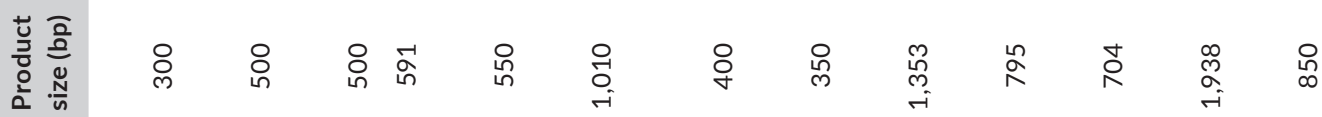

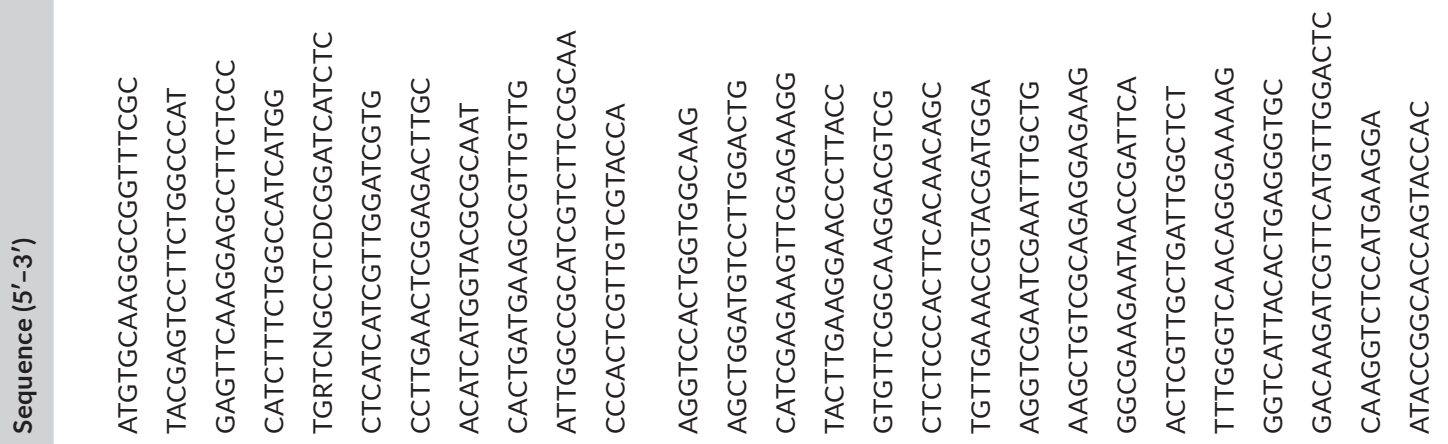

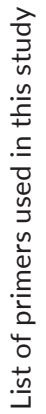
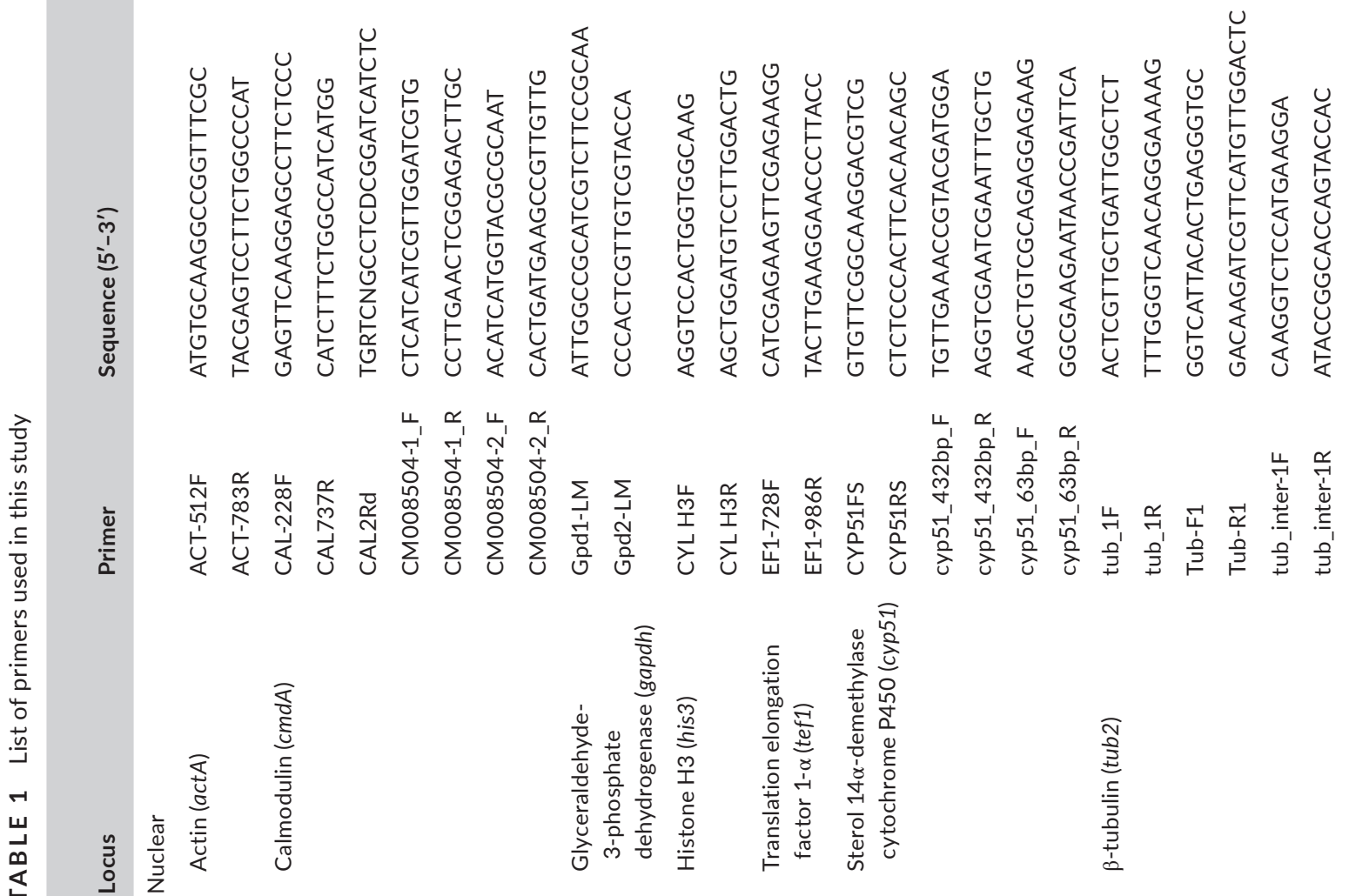


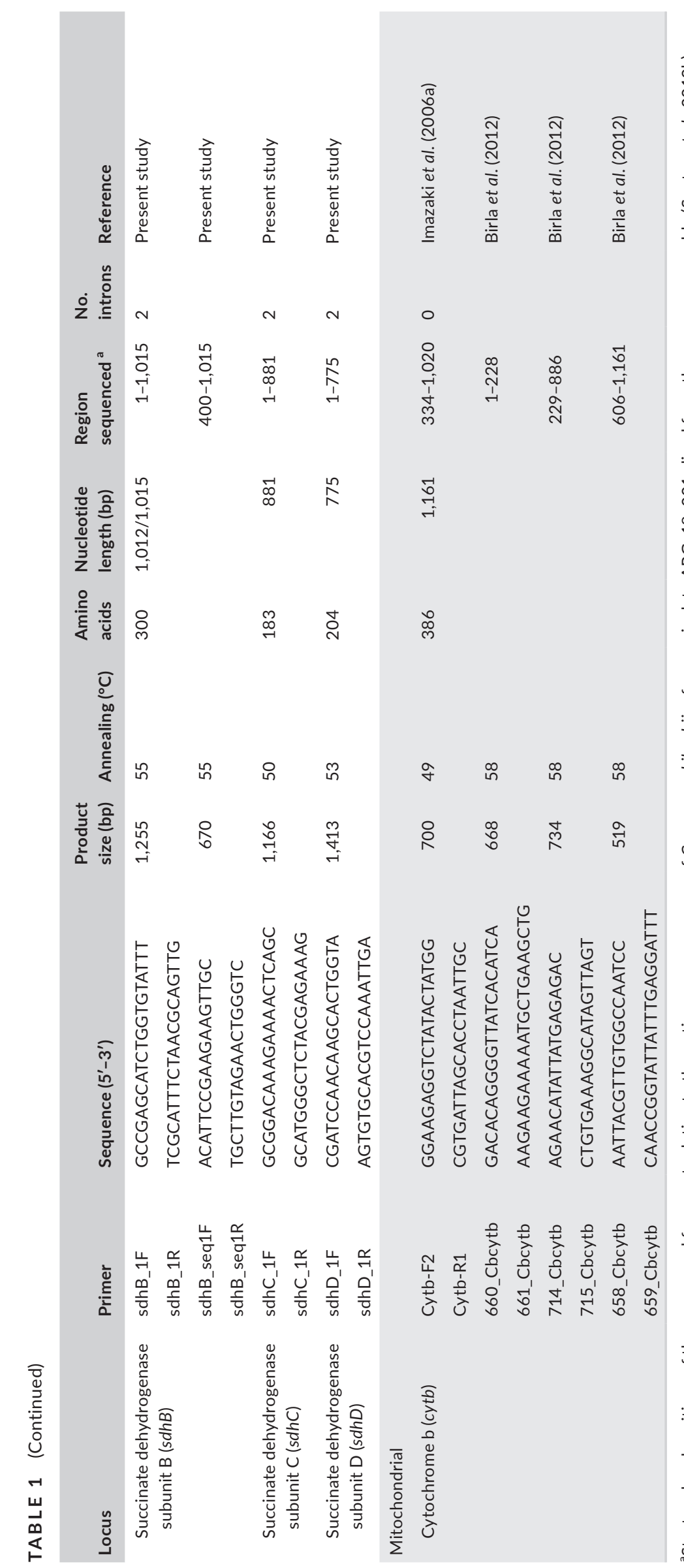


were as follows: concatenated, 3,354 sites (626 PIC); nrITS, 652 sites (14 PIC); actA, 234 sites (72 PIC); cmdA, 465 sites (103 PIC); his3, 400 sites (90 PIC); tef1, 684 sites (142 PIC); gapdh, 919 sites (205 PIC). The maximum-likelihood phylogeny for each gene and the concatenated alignment were estimated using the parallel AVX version of RAxML v. 8.2.12 (Stamatakis, 2014) specifying the GTR model of nucleotide evolution and $a$ distribution on rate heterogeneity across sites. Bipartition support was estimated with 1,000 bootstrap replicates for each analysis (mpirun raxmlHPCMPI-AVX -f a -x 12345 -p 12345 -\# 1000 -m GTRGAMMA). Prior to Bayesian inference, the best-fit model of nucleotide evolution and best partitioning scheme across alignments was estimated in Partition Finder 2 (Lanfear et al., 2016), specifying the greedy algorithm (Lanfear et al., 2012) with linked branch lengths and using the corrected Akaike information criterion for selecting the bestfit model among the set of models considered for MrBayes. The models selected were SYM $+I+\Gamma$ for nrITS and GTR $+I+\Gamma$ for $\operatorname{act} A, c m d A$, his3, tef1, and gapdh. The joint posterior distribution of parameter values and tree topologies for the concatenated, partitioned multilocus dataset was estimated in MrBayes v. 3.2.6 (Ronquist et al., 2012) with four replicate Markov chain Monte Carlo (MCMC) runs, four Metropolis-coupled chains per run (one cold and three heated), and 2.5 million generations per run with a sampling frequency of 1,000 . Convergence was determined by observing a standard deviation of split frequencies below 0.1 and effective sample sizes (ESS) above 200 for most parameters, discarding the first $50 \%$ of samples as burn-in. The majority-rule consensus phylogeny was computed using SumTrees v. 4.3.0 in Dendropy v. 4.3.0 (Sukumaran and Holder, 2010). The bipartitions with a posterior probability equal to or greater than 0.85 were mapped, if present, to the maximum-likelihood phylogeny alongside the maximum-likelihood bootstrap support values greater than $50 \%$. Species assignments were based on the results of the concatenated phylogenetic analyses and comparisons with each single-locus phylogenetic analysis. In order to assess the sensitivity of our results to missing data for gapdh and nrITS, we ran phylogenetic analyses that both included and excluded gapdh as well as including and excluding nrITS in the concatenated analyses and running multiple single-gene analyses. There was remarkable congruence across the analyses and no strongly supported conflict, suggesting that the missing data do not affect the phylogenetic results in a significant way.

\subsection{Chemicals}

Five DMI (cyproconazole, difenoconazole, epoxiconazole, prothioconazole, and tebuconazole), three Qol (azoxystrobin, pyraclostrobin, and trifloxystrobin), one SDHI (boscalid), and one MBC (carbendazim) were used for sensitivity tests as technical-grade fungicides (>97\% active). These fungicides were provided by Agrofina S.A. and Nova S.A. Additionally, the SDHI fungicides fluxapyroxad (Sistiva, $33.3 \mathrm{~g}$ a.i./100 ml, BASF Argentina S.A.) and pydiflumetofen (Miravis, $20 \mathrm{~g}$ a.i./100 ml SC, Syngenta Agro S.A.), and a multisite fungicide, mancozeb (Manzate Pro Stick, 75 g a.i./kg DF, UPL Argentina S.A.), were included as their commercial formulation.

\section{6 | In vitro fungicide sensitivity testing}

Because of scant sporulation in culture and following Price et al. (2015), mycelial radial growth inhibition instead of spore germination assays were used for determining fungicide sensitivity. In order to calculate the effective fungicide concentration to inhibit $50 \%$ of fungal radial growth $\left(E C_{50}\right)$ for each isolate $\times$ fungicide combination, all fungicides were tested on isolates 1-35 (Table S1). This set of isolates included 32 isolates from Argentina and 3 isolates from Bolivia. The Bolivian isolates were included for comparative purposes because these strains were isolated from soybean fields that received a significantly higher number of fungicide applications and are resistant to Qol fungicides (Sautua et al., 2019a). PDA plates were amended with serial dilutions of each technical and commercial grade fungicide at 0.001, 0.01, $0.1,1,10$ and $100 \mu \mathrm{g} / \mathrm{ml}$. Stock solutions of technical grade formulations of each fungicide were prepared at concentrations of $10 \mathrm{mg} /$ $\mathrm{ml}$ and serially diluted in acetone. An accurate volume of $20 \mathrm{ml}$ PDA was measured with a Falcon tube and dispensed into each $9 \times 1.5 \mathrm{~cm}$ Petri dish. There were four replicates (Petri dishes) per concentration. As initial inoculum, $6 \mathrm{~mm}$-diameter mycelial discs were cut from the margins of 7-day-old stock cultures of each isolate actively growing on PDA using a \#3 corkborer, inverted, and transferred to amended PDA. Petri dishes were incubated under a $16 \mathrm{hr}$ fluorescent and nearultraviolet $/ 8 \mathrm{hr}$ darkness cycle at $24 \pm 1^{\circ} \mathrm{C}$. Non-fungicide-amended PDA served as the control. After incubation for 7 days, colony diameter was measured twice using a digital caliper. Each experiment was conducted using a randomized complete block design with incubator shelves serving as blocks. There were four replicates per isolate.

In a second set of experiments, discriminatory doses of each fungicide were used on isolates 36-65 (Table S1) in order to detect fungicide resistance. Because there are no previous studies in Argentina and there is only one previous study in the USA (Price et al., 2015), discriminatory doses of 10 and $100 \mu \mathrm{g} / \mathrm{ml}$ were selected based on preliminary research and according to $\mathrm{EC}_{50}$ values calculated from isolates 1 to 35 (Table S1). These experiments were conducted as described above. Isolates that were not inhibited at $100 \mu \mathrm{g} / \mathrm{ml}$ were considered completely resistant.

Both types of experiments $\left(\mathrm{EC}_{50}\right.$ and discriminatory dose to detect sensitivity) were repeated once for cyproconazole, difenoconazole, epoxiconazole, prothioconazole, tebuconazole, carbendazim, and mancozeb, and twice for azoxystrobin, pyraclostrobin, trifloxystrobin, boscalid, fluxapyroxad, and pydiflumetofen.

\subsection{Determination of alternative respiration}

Some fungi possess the ability to use an alternative oxidation (AOX) pathway (Ziogas et al., 1997); however, it is not known how 
frequently this process may occur spontaneously in vivo. It has also been documented that the in vitro growth of Qol-resistant isolates is inhibited only in the presence of AOX inhibitors. Nevertheless, Price et al. (2015) found that propyl gallate (an AOX inhibitor) did not significantly affect radial growth of Cercospora isolates from Louisiana, USA. In order to determine whether an AOX pathway was present in Cercospora isolates chosen for the present study, the effect of salicylhydroxamic acid (SHAM, 99\% active; Alfa Aesar) was examined on six Cercospora isolates in a preliminary experiment. Isolates 1, 8 , $9,10,31$, and 32 (Table S1) were selected at random for this purpose. Serial dilutions of SHAM were made in ethanol (95\%). Afterwards, PDA was amended with SHAM at 0, 30, 60, 100, and $200 \mu \mathrm{g} / \mathrm{ml}$. The experiment was conducted as described in Section 2.6. Radial growth of Cercospora was significantly reduced by SHAM at $200 \mu \mathrm{g} /$ $\mathrm{ml}(80 \%$ on average) but not at $60 \mu \mathrm{g} / \mathrm{ml}(<20 \%$ on average). Thus, assays including isolates 1-35 were conducted as in Section 2.6 to compare the effect of azoxystrobin on mycelial growth with and without the addition of SHAM to the media. SHAM was either added to a final concentration of $60 \mu \mathrm{g} / \mathrm{ml}$ or omitted for each concentration of fungicide. The experiment was repeated once.

\subsection{Sequence analysis of $c y t b$, tub2, cyp51, and sdh genes}

In order to assess DNA sequence variation between fungicide-sensitive and -resistant isolates, we amplified and sequenced fragments of the mitochondrial cytochrome $b$ (cytb) gene and the nuclear $\beta$-tubulin (tub2) gene using PCR for 64 of the 65 randomly chosen individuals and sequenced the complete genome of the $C$. kikuchii reference isolate ARG_18_001 (Sautua et al., 2019b). We also amplified and sequenced fragments of the sterol $14 \alpha$-demethylase cytochrome P450 (cyp51) gene for 36 isolates (isolates 1-36, Table S1). Additionally, for some randomly chosen isolates, we amplified and sequenced the complete sequence of cytb, tub2, and cyp51. Furthermore, we amplified and sequenced the complete sequence of genes encoding the $B, C$, and $D$ subunits of the $S D H I$ fungicide-targeted succinate dehydrogenase enzyme ( $s d h B, s d h C$, and $s d h D$ ) where mutations associated with SDHI resistance had been previously described in different fungi (Sierotzki and Scalliet, 2013). The summary of the loci sequenced for each isolate and used in both the phylogenetic and the mutation analyses is shown in Table S2. Primers and PCR conditions used in the present study are described in Table 1. New primers were designed for cyp51, tub2, $s d h B, s d h C$, and $s d h D$ using Primer3 v. 4.1.0 (Untergasser et al., 2012). Sequencing services were performed as described previously. Multiple sequence alignment was performed for each locus using MUSCLE (Edgar, 2004) and including the complete sequence from the genome of isolate ARG_18_001 as a reference. Conserved loci were detected in the reference genome sequence using $C$. beticola sequences of each locus recovered from the NCBI against a local BLAST database. Coding regions and introns for each locus were identified by comparing with the mentioned $C$. beticola sequences (Sautua et al., 2019b).

\section{9 | 3-D modelling of the sterol $14 \alpha$-demethylase protein}

In order to locate the positions of mutations within the 3-D structure of the C. kikuchii sterol $14 \alpha$-demethylase cytochrome $\mathrm{P} 450$ protein (CYP51), the enzyme structure was modelled by comparative protein modelling methods using the SWISS-MODEL server (http://swiss model.expasy.org). The modelling structure of the C. kikuchii CYP51 was obtained with the 5eah.1 template (Saccharomyces cerevisiae CYP51 complexed with difenoconazole) by the On-line Swiss-model software.

\subsection{0 | Data analysis}

Dose-response curves and $\mathrm{EC}_{50}$ values were generated for each isolate $\times$ fungicide combination (isolates 1-35). Function drm() from drc package v. 2.5-12 (Ritz et al., 2015) was used in the R environment v. 3.6.3 (R Core Team, 2020) for nonlinear regression analysis. A log-logistic model, specifically a Weibull type I four-parameter model, was fitted and estimation of parameters was based on the maximumlikelihood estimate as described in Carmona et al. (2017b). Mean $\mathrm{EC}_{50}$ values and their $95 \%$ confidence intervals were estimated by combining all the data from the two (or three) experiments and using the $\mathrm{ED}$ () function of the drc package. A normality test for $\mathrm{EC}_{50}$ values was performed using the Shapiro-Wilk test of normality with the stats package of R. In all cases, data were non-normally distributed. Therefore, a Kruskal-Wallis one-way analysis of variance was used with the stats package in $\mathrm{R}$ to assess for significant differences among distributions of $\mathrm{EC}_{50}$ values for the different fungicides. Dunn's multiple comparison test was used post hoc to compare distributions among fungicide a.i. ( $p=.05$ ) with the dunnTest() function of the FSA package in R (Ogle et al., 2019). For AOX analysis, mean $\mathrm{EC}_{50}$ values (or growth inhibition values at $100 \mu \mathrm{g} / \mathrm{ml}$ if EC $\mathrm{E}_{50}$ values could not be estimated due to resistance) for SHAM-amended PDA and nonamended PDA were compared using a two-sample $t$ test with the stats package in $\mathrm{R}$.

\section{3 | RESULTS}

\section{1 | Fungal isolates and pathogenicity tests}

All the fields sampled in all locations and in all years were infected with CLB/PSS with $100 \%$ prevalence, confirming that these diseases are fully distributed throughout Argentina and Santa Cruz, Bolivia. In all, 554 single-conidium isolates of Cercospora spp. were collected from different fields as follows: a total of 516 isolates were obtained from 67 locations in nine different provinces of Argentina in 2012 (1), 2014 (1), 2015 (20), 2016 (364), 2017 (67), 2018 (6), and 2019 (57); and 38 isolates were obtained from Santa Cruz, Bolivia in 2017. In Argentina, 196 isolates were collected from the northwest region, 241 isolates from the centre, and 74 isolates from the 
south-east (green, yellow, and orange GPS points in Figure S1, respectively). The north-east (two isolates) and west (three isolates) regions were not included as they were not represented in the same proportion as the rest. Within each region, the isolates were chosen randomly. In Argentina, 336 isolates were obtained from seeds, 177 from leaves, two from peduncles, and one from a pod, whereas the 38 Bolivian isolates were obtained from leaves. Of the 516 isolates from Argentina, 492 were collected from soybean, 10 from $A$. hybridus, and 14 from $A$. hortorum. All isolates were deposited in the fungal culture collection of the Plant Pathology Department of the University of Buenos Aires (FAUBA, Argentina).

All isolates were pathogenic to soybean leaves, causing blight symptoms typical of CLB within 21 days of inoculation. The results were confirmed in repeated experiments. All the inoculated varieties were infected and showed CLB symptoms. Disease incidence on inoculated plants was $100 \%$. There was no differential response among cultivars. Negative controls were symptomless. Leaves with symptoms were incubated in Petri dishes and isolates were recovered from all soybean varieties tested. Recovered isolates and monoconidial cultures resembled original inoculum on PDA, completing Koch's postulates.

\subsection{Species identification}

The 42 isolates from Argentina and Bolivia were distributed among eight lineages. The majority of previously circumscribed species represented by multiple isolates in the concatenated multilocus phylogeny were moderately to strongly supported as monophyletic in both the Bayesian and maximum-likelihood analyses (Figure 1). Those species that are paraphyletic or polyphyletic include $C$. chenopodii, C. apii, C. cf. flagellaris, C. richardiicola, and C. kikuchii. In each of these cases, other species are nested within the clade that otherwise includes conspecific isolates. C. pseudochenopodii is nested within the clade that includes isolates of $C$. chenopodii. Isolates of $C$. uwebrauniana and C. gamsiana are nested within the clade that includes all isolates of C. apii. C. cf. flagellaris isolates are partitioned into multiple subclades that include isolates of $C$. gossypii, $C$. cf. brunkii, and C. convolvulicola. C. richardiicola is polyphyletic with C. sigesbeckiae, C. sp. N, C. sp. M, and C. rodmanii, and is referred to as the C. richardiicola complex (CRC) below. Finally, C. kikuchii is paraphyletic with C. cf. maloti, C. sp. O, C. sp. Q, and C. sp. P nested within the clade that includes all isolates of $C$. kikuchii. This clade that includes isolates of $C$. kikuchii, which we refer to as the $C$. kikuchii complex $(\mathrm{CKC})$, contains the majority of the isolates collected for this study, including 30 isolates from Argentina (one collected in 2014, 25 in 2016, one in 2018, and three in 2019) and one isolate from Bolivia. Of these isolates, 30 are assigned to $C$. kikuchii based on the multilocus concatenated analysis and the remaining isolate, 19_057 from Argentina, is assigned to $C$. sp. O despite it being weakly supported as sister to a single isolate of $C$. sp. O. Five of the remaining 11 isolates were nested within the CRC, and four of these (ARG_16_080, ARG_16_120, ARG_16_227, and BOL_17_026) are denoted as such

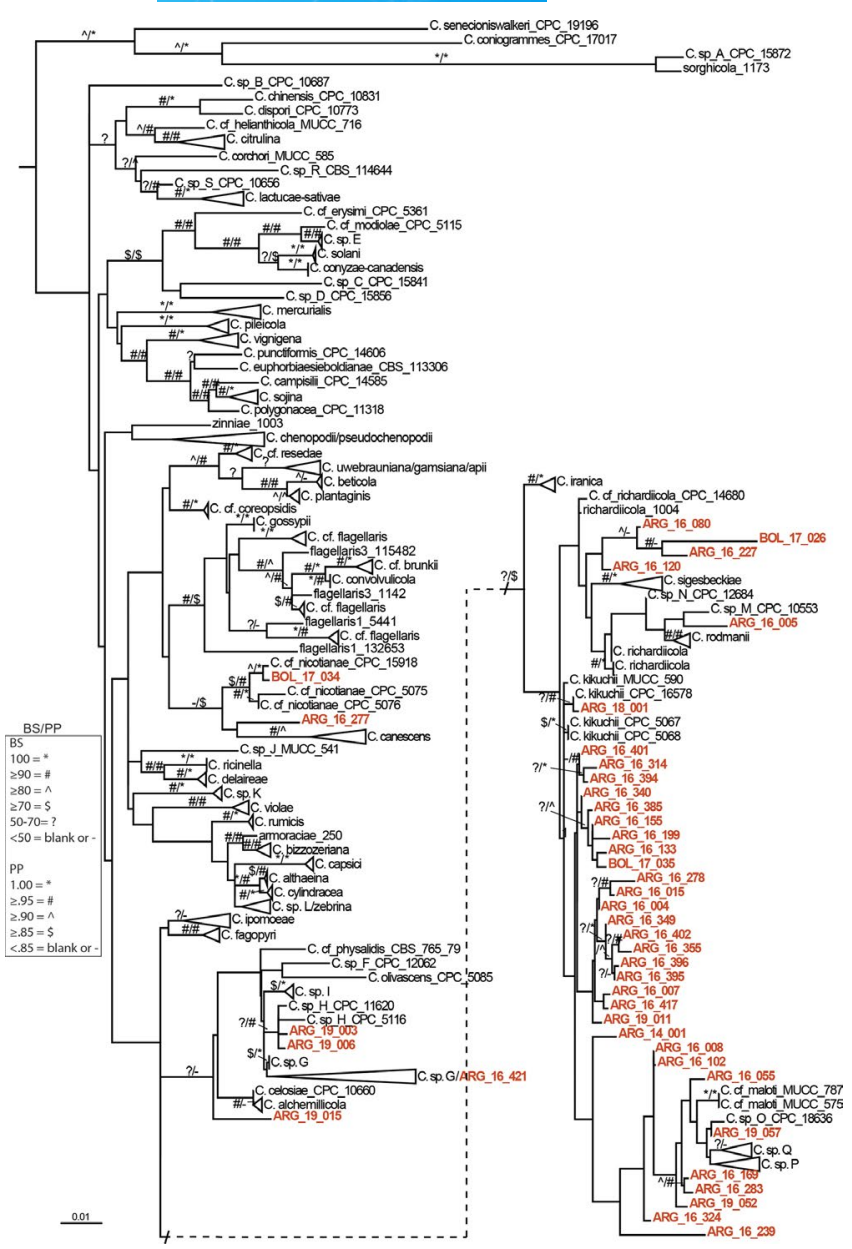

FIGURE 1 Maximum-likelihood phylogeny of the genus Cercospora inferred from a concatenated alignment of nrITS, actA, $\mathrm{cmdA}$, gapdh, tef1, and his3. Isolates collected and sequenced for this study are highlighted in bold red font. The tree is rooted with Septoria provencialis. Some clades that are not the focus of this study have been collapsed for visualization purposes. Maximumlikelihood bootstrap support (BS) values greater than $50 \%$ and Bayesian posterior probabilities (PP) greater than 0.85 are shown on the branches (BS/PP). Symbols represent the range of values indicated in the legend. Unlabelled branches were found in the maximum-likelihood tree search, but were not found at a frequency greater than or equal to $50 \%$ among the bootstrap replicate searches and were not present or received low support $(<0.85)$ in the Bayesian analysis. The scale bar represents the estimated number of substitutions per site [Colour figure can be viewed at wileyonlinelibrary.com]

in Table S1 because their affinity with any previously described species is unclear based on the phylogenetic results. A single isolate within the CRC was assigned to $C$. sp. $M$ based on a weakly supported sister relationship to a single isolate of $C$. sp. $M$ (C. sp. M_CPC_10553). Four of the six remaining isolates were assigned to C. sp. H (ARG_19_003, ARG_19_006), C. sp. G (ARG_16_421), and C. nicotianae (BOL_17_034). The last two isolates could not be definitively assigned to species based on their uncertain placement in the concatenated phylogeny. ARG_16_277 was weakly supported as sister to $C$. canescens in the multilocus concatenated phylogeny, but 
in the gapdh, tef1, and his 3 phylogenies this isolate was strongly supported as sister to BOL_17_034, thus it was assigned to C. nicotianae in Table S1. The last remaining isolate, ARG_19_015, was not assigned to a species (species indet.) in Table $\mathrm{S} 1$ because its placement varied considerably among individual locus phylogenies. This isolate was weakly supported as sister to $C$. $\mathrm{sp}$. $\mathrm{H}$ in the actA phylogeny, uncertain in his3, weakly supported as sister to C. sp. G in tef1, strongly supported as nested within C. sp. G in gapdh, and closely related to isolates of $C$. kikuchii and $C$. fagopyri, albeit with weak support, in the cmdA phylogeny. This is the first report of $C$. kikuchii and $C$. sp. O isolated from $A$. hortorum, and $C$. sp. $\mathrm{H}$ from $A$. hybridus.

\section{3 | Determination of alternative respiration}

While all isolates were extremely resistant to the Qol fungicides tested and the $\mathrm{EC}_{50}$ values could not be estimated, there were no significant differences when comparing between mycelial growth inhibition values with and without the addition of SHAM at a given fungicide concentration. This was observed in 35 isolates of Cercospora (data not shown). These results are in agreement with those of Price et al. (2015). Therefore, it was assumed that for the isolates tested here, AOX did not occur, and SHAM was not used in subsequent experiments. Nevertheless, future experiments including sensitive isolates should elucidate whether or not the AOX pathway is present in Cercospora isolates from Argentina.

\subsection{Activity of fungicides against mycelial growth and nucleotide and amino acid sequences of cytb, tub2, cyp51, and sdh genes}

\subsection{1 | DMI}

A total of 62 Argentinian isolates were sensitive to all DMls tested. $\mathrm{EC}_{50}$ values of DMIs estimated in 32 Argentinian isolates ranged from 0.006 to $0.094 \mu \mathrm{g} / \mathrm{ml}$ for difenoconazole, from 0.024 to $0.545 \mu \mathrm{g} /$ $\mathrm{ml}$ for prothioconazole, from 0.022 to $0.577 \mu \mathrm{g} / \mathrm{ml}$ for epoxiconazole, from 0.055 to $1.762 \mu \mathrm{g} / \mathrm{ml}$ for tebuconazole, and from 0.164 to $2.371 \mu \mathrm{g} / \mathrm{ml}$ for cyproconazole (isolates 1-32 in Tables S1 and S4). Among the five DMI fungicides tested, difenoconazole exhibited the highest fungitoxicity (Figure 2; Table 2). Prothioconazole and epoxiconazole did not differ from each other $(p=1)$, being less fungitoxic than difenoconazole but more fungitoxic than tebuconazole and cyproconazole, which also did not differ from each other $(p=1)$. Two Bolivian isolates (numbers 33 and 34 ) were sensitive to all DMI fungicides and one isolate (number 35, C. kikuchii) was the only strain considered resistant to cyproconazole $\left(\mathrm{EC}_{50}=45.8 \mu \mathrm{g} / \mathrm{ml}\right)$ and tebuconazole $\left(\mathrm{EC}_{50}=10 \mu \mathrm{g} / \mathrm{ml}\right.$ ) and less sensitive to prothioconazole $\left(\mathrm{EC}_{50}=6 \mu \mathrm{g} / \mathrm{ml}\right)$. Cyproconazole was the least fungitoxic, with a 14.5- and 107.4-fold range of $\mathrm{EC}_{50}$ values for the Argentinian and Bolivian isolates, respectively (max/min values in Table S4). Based on these results, two discriminatory doses were chosen to test new

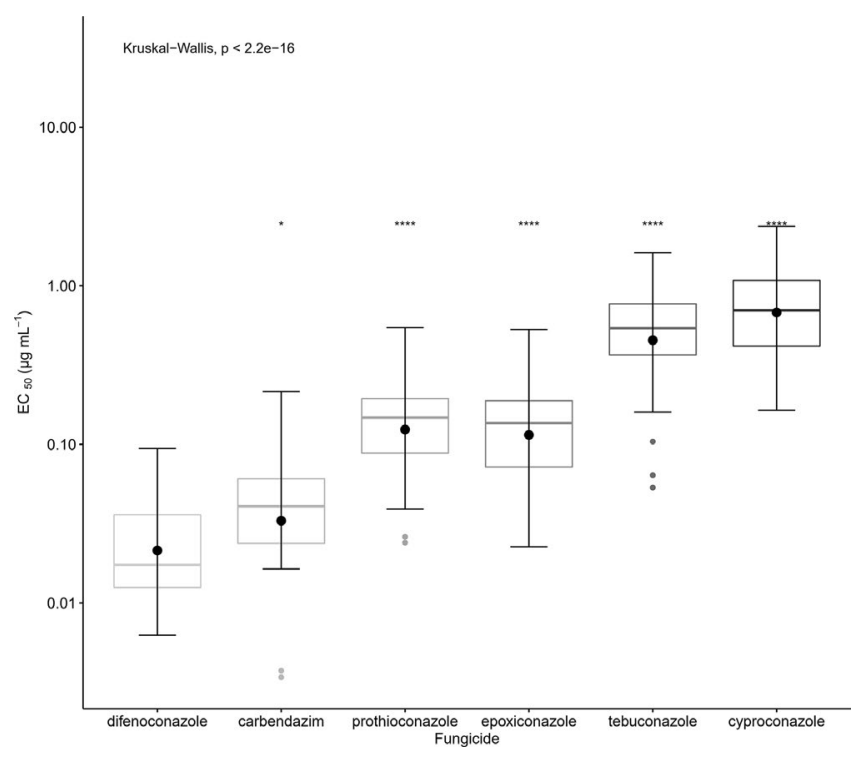

FIGURE 2 Sensitivity distribution ( $\mathrm{EC}_{50}$ ) of 32 and 19 Argentinian Cercospora isolates causing cercospora leaf blight/ purple seed stain to five demethylation inhibitors (DMIs) and to carbendazim (MBC), respectively. Pairwise comparisons using the Wilcoxon rank sum test (Mann-Whitney $U$ test) are shown against difenoconazole, the most fungitoxic active ingredient against all Cercospora isolates tested in the present study

TABLE 2 Average fungicide effective concentration required to inhibit mycelial growth by $50 \%\left(\mathrm{EC}_{50}\right)$ in Argentinian isolates of Cercospora sensitive to $\mathrm{DMI}$ and carbendazim (MBC), resistant to Qol, and insensitive to SDHI and mancozeb

\begin{tabular}{|llll}
\hline Active ingredient & $\begin{array}{l}\text { Mode of } \\
\text { action }\end{array}$ & $\begin{array}{l}\text { No. isolates } \\
\text { tested }\end{array}$ & $\begin{array}{l}\mathrm{EC}_{50} \\
(\mu \mathrm{g} / \mathrm{ml})\end{array}$ \\
\hline Difenoconazole & DMI & 32 & $0.027 \mathrm{a}$ \\
\hline Carbendazim & MBC & 19 & $0.048 \mathrm{ab}$ \\
\hline Prothioconazole & DMI & 32 & $0.157 \mathrm{~b}$ \\
\hline Epoxiconazole & DMI & 32 & $0.154 \mathrm{~b}$ \\
\hline Tebuconazole & DMI & 32 & $0.602 \mathrm{c}$ \\
\hline Cyproconazole & DMI & 32 & $0.889 \mathrm{c}$ \\
\hline Azoxystrobin & Qol & 62 & $>100$ \\
\hline Pyraclostrobin & Qol & 62 & $>100$ \\
\hline Trifloxystrobin & Qol & 62 & $>100$ \\
\hline Boscalid & SDHI & 62 & $>100$ \\
\hline Pydiflumetofen & SDHI & 62 & $>100$ \\
\hline Fluxapyroxad & SDHI & 62 & $>100$ \\
\hline Mancozeb & Multisite & 62 & $>10$ \\
\hline
\end{tabular}

Note: Means followed by the same letter do not significantly differ as determined by Kruskal-Wallis one-way analysis of variance followed by Dunn's multiple comparison test. All 62 Argentinian isolates were completely resistant or insensitive to Qol and SDHI fungicides, respectively.

isolates in a new round of experiments: $10 \mu \mathrm{g} / \mathrm{ml}$ allows for the detection of decreased sensitivity and $100 \mu \mathrm{g} / \mathrm{ml}$ allows for the detection and confirmation of extremely resistant isolates. The other 30 
Argentinian isolates (nos. 36-65, Table S1) exposed to discriminatory doses of each DMI fungicide were sensitive to all fungicides tested, confirming the lack of variation in sensitivity with respect to the oldest isolates (Table 3).

Despite having found 103 single nucleotide polymorphisms (SNPs) along the cyp51 partial sequence in $16 \mathrm{DMI}$-sensitive isolates, no apparent mutations known to be associated with DMI resistance in Cercospora or other fungi were found in the 32 Argentinian and 2 Bolivian sensitive isolates sequenced. Most of the SNPs found ( $84 \%$, $87 / 103$ ) were synonymous substitutions and thus did not alter the amino acid sequence. There is no clear correlation or association between SNPs and Cercospora species at this locus. The only observed pattern corresponded to 19 SNPs shared by 14 isolates of different species (C. kikuchii, C. nicotianae, CRC, C. sp. M, C. sp. G). Nevertheless, two new single-nucleotide mutations detected in the cyp51 gene of the DMI-resistant Bolivian isolate BOL_2017_035 resulted in the amino acid substitutions I387M and D440N. The complete amino acid sequence for the CYP51 enzyme and the modelling structure of the CYP51 of isolate C. kikuchii BOL_17_035 are shown in Figures S2 and S3, respectively. According to the modelling structure of the CYP51 of DMI-resistant isolate C. kikuchii BOL_17_035, the mutation I387M is present in a residue next to the prosthetic heme group (Figure S3).

\subsection{2 | Carbendazim (MBC)}

In total, 33 isolates were sensitive and 32 were resistant to carbendazim, the only MBC fungicide tested. Carbendazim had a high

TAB LE 3 Inhibition of mycelial growth of sensitive or insensitive/resistant Cercospora spp. isolates exposed to discriminatory doses of different fungicides

\begin{tabular}{|c|c|c|c|c|c|c|}
\hline Fungicide & \multicolumn{3}{|l|}{ Sensitive } & \multicolumn{3}{|c|}{ Resistant or insensitive } \\
\hline \multicolumn{7}{|l|}{ Argentina } \\
\hline Difenoconazole & 62 & $98(92-100)$ & $100(100-100)$ & 0 & - & - \\
\hline Tebuconazole & 62 & $88(72-100)$ & $100(100-100)$ & 0 & - & - \\
\hline Cyproconazole & 62 & $82(71-99)$ & $100(100-100)$ & 0 & - & - \\
\hline Carbendazim & 33 & $100(100-100)$ & $100(100-100)$ & 29 & $0(0-0)$ & $6(0-19)$ \\
\hline Azoxystrobin & 0 & - & - & 62 & $25(0-49)$ & $33(21-48)$ \\
\hline Fluxapyroxad & 0 & - & - & 62 & $11(3-20)$ & $12(3-52)$ \\
\hline Pydiflumetofen & 0 & - & - & 62 & $20(2-41)$ & $23(3-58)$ \\
\hline Mancozeb & 0 & - & - & 62 & $37(19-40)$ & $100(100-100)$ \\
\hline \multicolumn{7}{|l|}{ Bolivia } \\
\hline Difenoconazole & 3 & $94(93-96)$ & $100(100-100)$ & 0 & - & - \\
\hline Prothioconazole & 3 & $72(62-85)$ & $100(100-100)$ & 0 & - & - \\
\hline Epoxiconazole & 3 & $85(82-90)$ & $100(100-100)$ & 0 & - & - \\
\hline Tebuconazole & 2 & $63-70$ & $100-100$ & $1^{\mathrm{a}}$ & 51 & 85 \\
\hline Fluxapyroxad & 0 & - & - & 3 & $13(4-19)$ & $11(2-36)$ \\
\hline Pydiflumetofen & 0 & - & - & 3 & $19(14-25)$ & $21(3-44)$ \\
\hline Mancozeb & 0 & - & - & 3 & $31(24-42)$ & $100(100-100)$ \\
\hline
\end{tabular}

alsolate BOL_2017_035. 
fungitoxicity on 19 Argentinian sensitive isolates with $\mathrm{EC}_{50}$ values ranging from 0.003 to $0.2 \mu \mathrm{g} / \mathrm{ml}$ (Table S4). These $\mathrm{EC}_{50}$ values did not significantly differ from difenoconazole $(p=1)$, epoxiconazole ( $p=.1$ ) or prothioconazole ( $p=.06$; Table 2; Figure 2 ). In the 33 sensitive isolates (19 from isolates 1 to 35 and 14 from isolates 36 to 65), the mycelial growth was inhibited $100 \%$ at $10 \mu \mathrm{g} / \mathrm{ml}$. However, in the other 32 resistant isolates tested ( 16 from isolates 1 to 35 and 16 from isolates 36 to 65 ) carbendazim at $10 \mu \mathrm{g} / \mathrm{ml}$ did not inhibit any isolate ( $0 \%$ inhibition of the mycelial growth) and at $100 \mu \mathrm{g} / \mathrm{ml}$ inhibited between $0 \%$ and $19 \%$, but $78 \%$ of these resistant isolates $(25 / 32)$ had a percentage inhibition of $10 \%$ or less (Table 3$)$.

The E198A mutation was the only mutation detected in the partial sequence of the tub2 gene in 31 of 32 isolates found resistant to carbendazim. One resistant isolate (ARG_19_016) does not have this mutation or any other mutation in the entire tub2 gene. The percentage of mycelial growth inhibition for this isolate was $0 \%$ and $19 \%$ at $10 \mu \mathrm{g} / \mathrm{ml}$ and $100 \mu \mathrm{g} / \mathrm{ml}$, respectively.

The $C$. kikuchii $\beta$-tubulin protein is coded by a 1,611 bp gene with four introns (Table 1). This gene is highly conserved; no differences were observed in the partial or complete exon sequences between species or between any isolate. Although a few intronic SNPs were found in the entire tub2 sequence for eight isolates, including the $C$. kikuchii, C. nicotianae, and CRC species (nine, nine, eight, and four SNPs in introns 1, 2, 3, and 4, respectively), no clear association was observed between intron sequences and assigned species. The complete amino acid sequence for the $\beta$-tubulin protein is shown in Figure S4.

\subsection{3 | Qol}

Because no differences in mycelial growth inhibition were observed in any isolate along the concentration gradient used in the in vitro sensitivity tests of azoxystrobin, trifloxystrobin, and pyraclostrobin, $\mathrm{EC}_{50}$ values could not be estimated $\left(\mathrm{EC}_{50}>100 \mu \mathrm{g} / \mathrm{ml}\right.$; Table 2). Mycelial growth of all 65 isolates was highly insensitive to these fungicides as none of them were $100 \%$ inhibited when exposed at the highest concentration tested $(100 \mu \mathrm{g} / \mathrm{ml})$. The 62 Argentinian isolates had a mycelial inhibition range of $0 \%-49 \%, 18 \%-39 \%$, and 29\%-53\% for azoxystrobin, trifloxystrobin, and pyraclostrobin, respectively, at $10 \mu \mathrm{g} / \mathrm{ml}$; and a range of $21 \%-48 \%, 24 \%-48 \%$, and $37 \%-59 \%$, respectively, at $100 \mu \mathrm{g} / \mathrm{ml}$ (Table 3). Because none of the Qol tested suppressed mycelial growth at $100 \mu \mathrm{g} / \mathrm{ml}$ for any of the isolates tested, we consider these isolates strobilurin-resistant.

Although 65 isolates tested in this study were found to be resistant to Qol fungicides, the G143A mutation was detected in the cytb gene of only 53 isolates ( $82 \%$; Table 4 ). In order to rule out sequencing errors, the 12 isolates that do not possess the G143A mutation were sequenced separately and independently, and the complete $c y t b$ gene was amplified and sequenced. No mutations associated with Qol resistance, F129L and G137R, nor any other mutation was found in the partial or complete sequence of this gene in any tested isolate. The C. kikuchii cytochrome b protein is coded by a 1,161 bp intron-free gene (Table 1). This gene is highly conserved; no differences were observed in the partial or complete sequence among isolates. The complete amino acid sequence for the cytochrome $b$ protein is shown in Figure S5.

\subsection{4 | SDHI}

All isolates in this study were insensitive to boscalid, fluxapyroxad, and pydiflumetofen. Mycelial growth of all 65 isolates was highly insensitive to SDHI fungicides as none of them were $100 \%$ inhibited when exposed to the highest concentration tested $(100 \mu \mathrm{g} /$ $\mathrm{ml})$. The 62 Argentinian isolates had a mycelial inhibition range of $0 \%-36 \%, 3 \%-20 \%$, and $2 \%-41 \%$ for boscalid, fluxapyroxad, and pydiflumetofen, respectively, at $10 \mu \mathrm{g} / \mathrm{ml}$; and a range of $0 \%-40 \%$, $3 \%-52 \%$, and $3 \%-58 \%$, respectively, at $100 \mu \mathrm{g} / \mathrm{ml}$ (Table 3).

There were no mutations present in the $s d h B, s d h C$, and $s d h D$ genes sequenced in a subset of 11 isolates for $s d h B$ and $s d h C$ and eight isolates for $s d h D$. The $C$. kikuchii SDHB, SDHC, and SDHD proteins are coded by $1,015,881$, and 775 bp genes, respectively, with two introns each (Table 1). The three loci are highly conserved; no differences were observed in the complete sequence between species or between any isolate. A few intronic SNPs were found in the entire $s d h B, s d h C$, and $s d h D$ sequences for 11 isolates, including the C. kikuchii, C. nicotianae, C. sp. G, and CRC species (11 and 8 SNPs in introns 1 and 2, respectively, for sdhB; zero and one SNP in introns 1 and 2, respectively, for $s d h C$; one and zero SNP in introns 1 and 2, respectively, for $s d h D$ ). No clear association was observed between intron sequences and assigned species. The complete amino acid sequences for SDHB, SDHC, and SDHD proteins for these isolates are shown in Figures S6-S8.

\subsection{5 | Mancozeb (multisite)}

All isolates tested were insensitive to mancozeb at $10 \mu \mathrm{g} / \mathrm{ml}$, with a mycelial growth inhibition range of $19 \%-40 \%$ for the Argentinian isolates. However, all isolates were completely inhibited (100\%) at $100 \mu \mathrm{g} / \mathrm{ml}$ (Table 3).

Lastly, the results were consistent between the first and second round of tests (the first to estimate $\mathrm{EC}_{50}$ values and the second to use discriminatory doses to detect loss of sensitivity or resistance) for all fungicide modes of action and a.i. here evaluated. We did not find any impact of species in sensitivity to different a.i. The mycelial growth inhibition versus concentration of each a.i. are shown in Figures S9-S30.

\section{4 | DISCUSSION}

To our knowledge, this is the first study in Argentina investigating sensitivity of Cercospora species causing CLB/PSS to technical and commercial grade fungicides from different MoA groups. In total, 65 


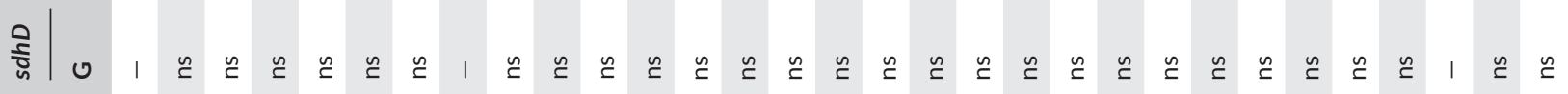

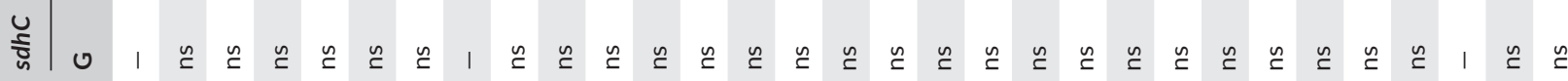

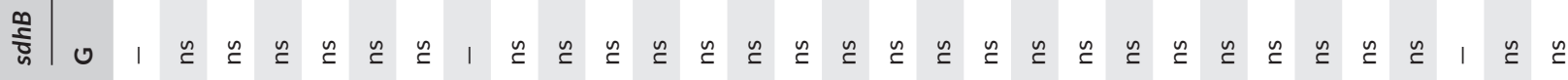
ज̆

in

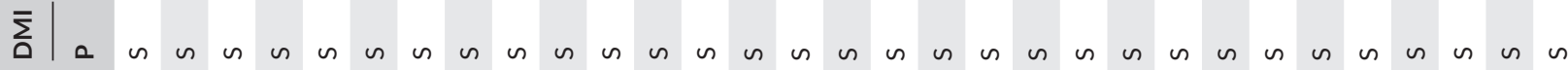

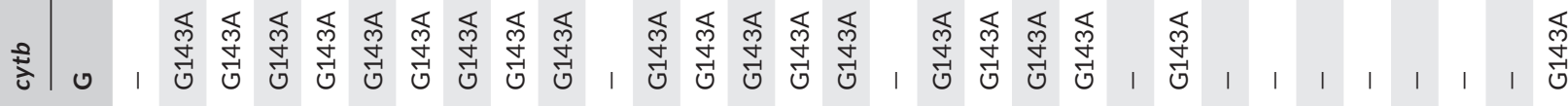

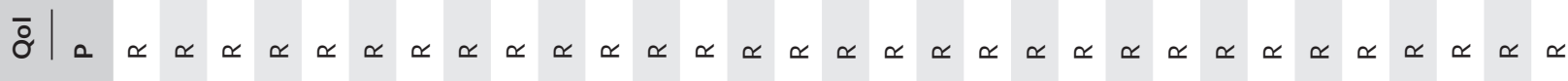

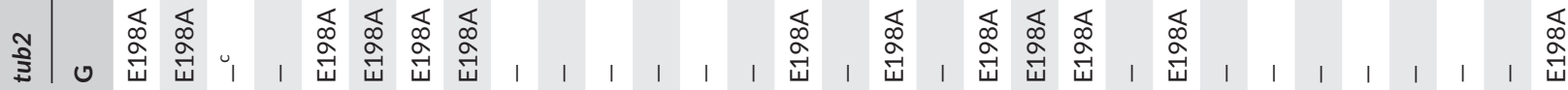

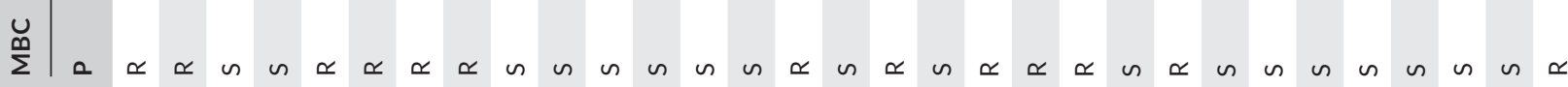

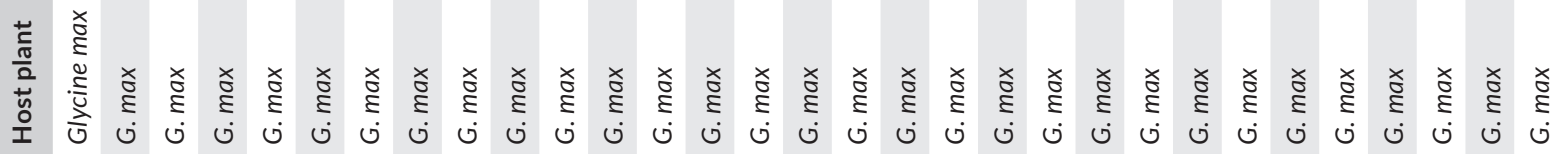

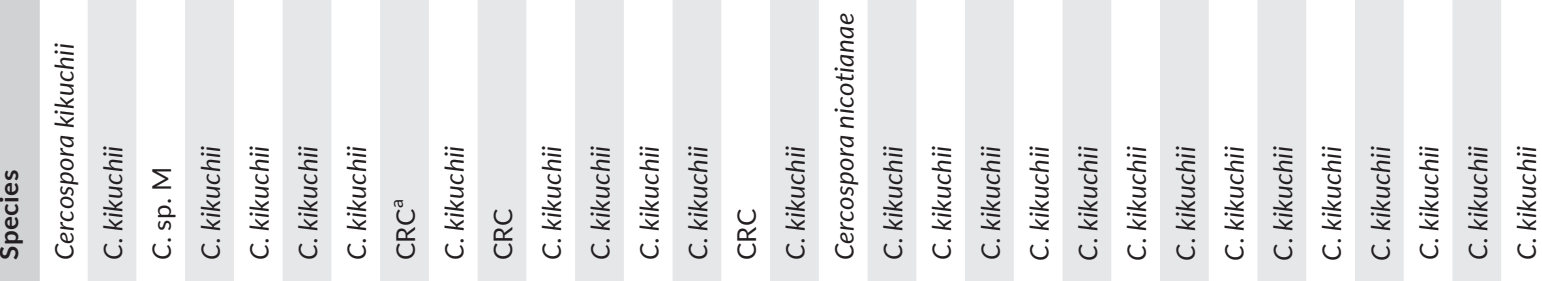

రั

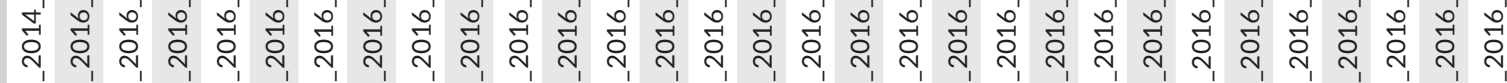

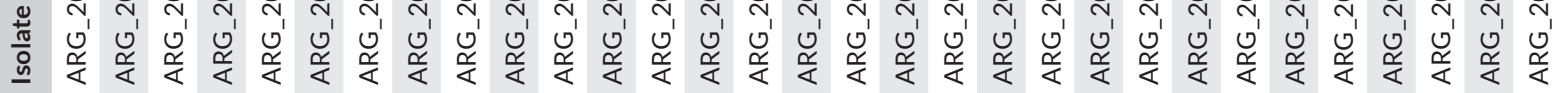




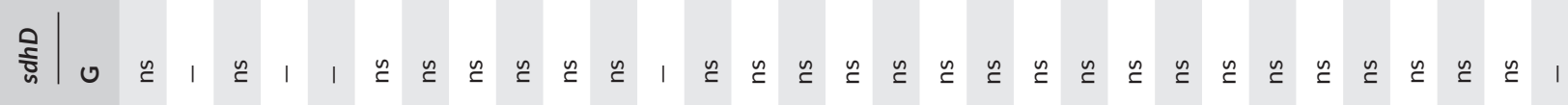

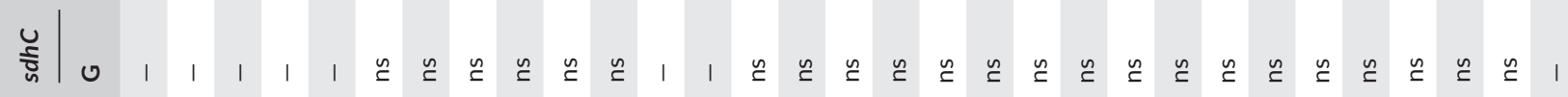

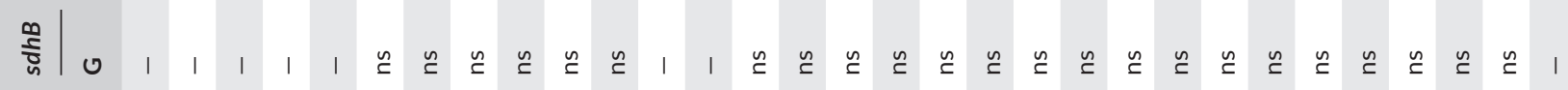
公|

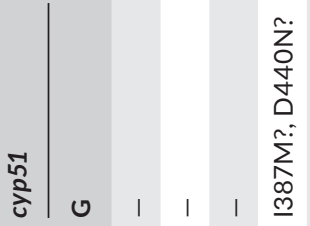

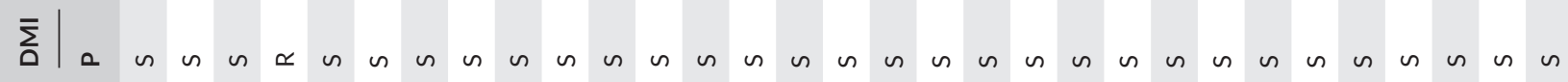

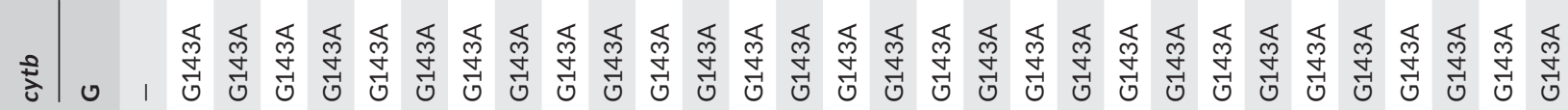

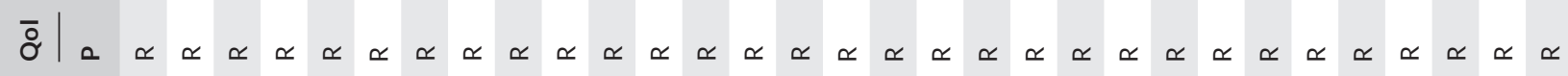

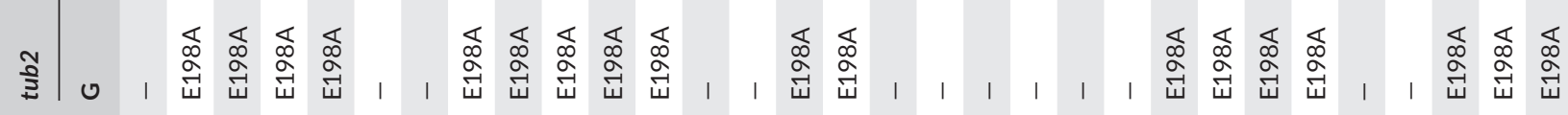
एٕ

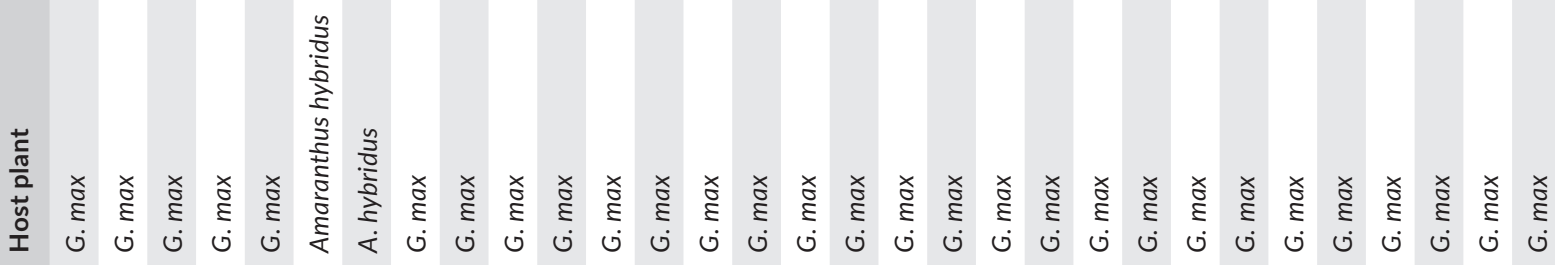

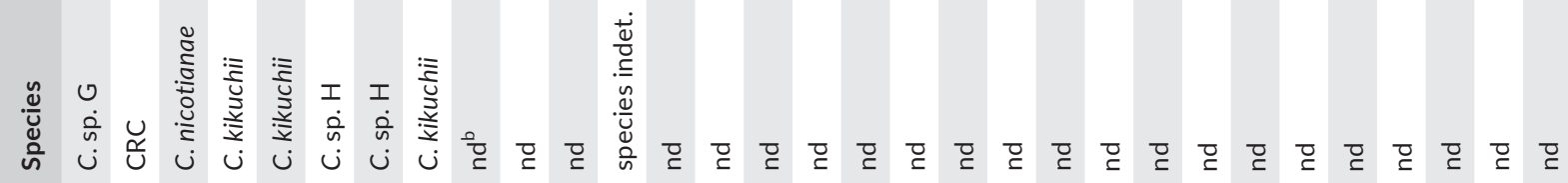

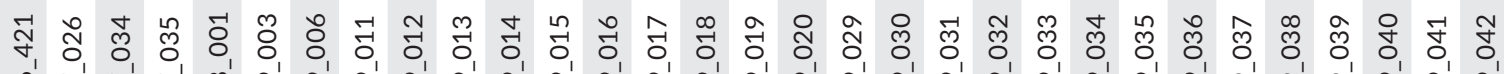

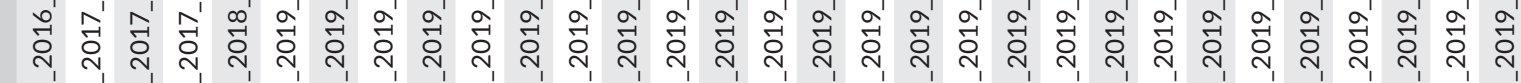

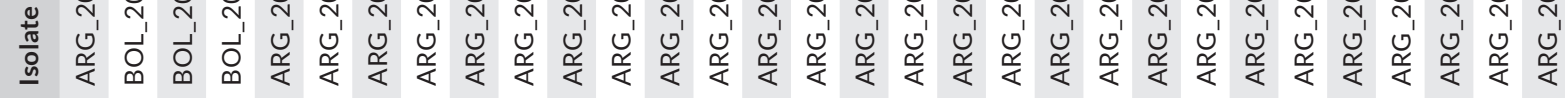




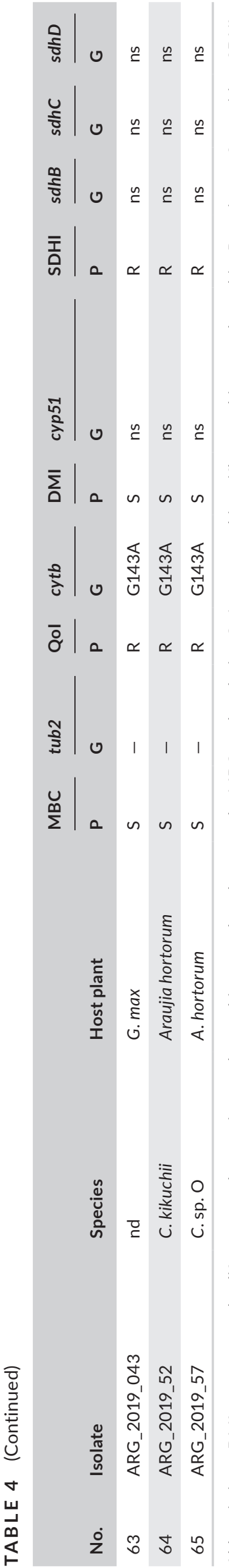

Cercospora isolates were tested, and were highly resistant to Qol, and half of these isolates were highly resistant to carbendazim. Similarly, Cercospora isolates were reported resistant to Qol and MBC fungicides in Louisiana, USA (Price et al., 2015). All isolates tested here were insensitive to SDHI fungicides. In contrast, all tested isolates were sensitive to the DMI fungicides, except for one $C$. kikuchii isolate from Bolivia (BOL_17_035).

All Qol molecules tested (azoxystrobin, trifloxystrobin, and pyraclostrobin) were ineffective against all isolates, indicating that these isolates possess cross-resistance to multiple Qol fungicides. It was not possible to test picoxystrobin in this study, but we speculate that it would most likely exhibit a similar response against the Cercospora isolates tested here, as cross-resistance was reported in the in vitro tests, and field observations from location Alejo Ledesma, where isolates 49-56 were recovered, showed that plots were heavily infected with CLB/PSS after being treated twice with a picoxystrobin + cyproconazole mixture $(300 \mathrm{ml} / \mathrm{ha})$.

In general, Qol-resistance and MBC-resistance in ascomycetes are usually caused by mutations in the cytb and tub2 genes, respectively (Imazaki et al., 2006a). In the present study, we identified the most frequently found mutations that are known to confer resistance to Qols and MBCs in the majority of tested isolates.

In Argentina, the G143A mutation in the cytb gene was the only one found in most of the isolates tested that contributed to the field control failures of CLB treated with Qols, and a similar situation in USA and Bolivia has been observed (Price et al., 2015; Sautua et al., 2019a). No other known mutations, such as the F129L and G137R (Sierotzki, 2015), were identified in this gene among the 65 sequenced isolates. The G143A mutation is the most frequent mutation associated with resistance to Qol fungicides in plant pathogens (Sierotzki, 2015). However, although all isolates tested were resistant to all Qols, we only detected the G143A mutation in the cytb gene in $82 \%$ of these isolates. Thus, it might be possible that factor(s) other than target-site modification are involved in the resistance of Cercospora species to Qol fungicides. For example, Vielba-Fernández et al. (2018) recently reported on the role of mitochondrial heteroplasmy for the cytb gene in Podosphaera xanthii as a mechanism explaining resistance to Qols. Their findings suggest that the proportion of G143 and A143 alleles in an isolate may determine the Qol resistance level.

Similarly, in this study the E198A mutation in the tub2 gene was present in 31 of $32(97 \%)$ isolates resistant to carbendazim. No other mutation was found in the full-length sequence of tub2, suggesting that mechanism(s) other than fungicide target-site modification may confer resistance to carbendazim. In Japan, MBC-resistance was attributed to the E198A mutation only, as 154 of 247 (62.3\%) isolates of $C$. kikuchii were highly resistant to thiophanate-methyl (MBC) and the 12 resistant isolates that were sequenced possessed the E198A mutation (Imazaki et al., 2006b).

On the other hand, boscalid, fluxapyroxad, and pydiflumetofen were ineffective against all isolates tested here. For instance, at $10 \mu \mathrm{g} / \mathrm{ml}$ boscalid and fluxapyroxad/pydiflumetofen had an average inhibition percentage of $9 \%, 11 \%$, and $20 \%$ in the 62 Argentinian 
Cercospora isolates, respectively, whereas Corynespora cassiicola isolates from cucumber in Japan highly resistant to boscalid had $\mathrm{EC}_{50}$ values from 8.9 to $10.7 \mu \mathrm{g} / \mathrm{ml}$ (Miyamoto et al., 2010). The H278Y and H278R mutations in the $s d h B$ subunit were responsible for the resistance (Miyamoto et al., 2010). However, in the present study, no mutations were found in the complete sequence of the $s d h B, s d h C$, and $s d h D$ genes of the sequenced isolates. Moreover, in Argentina SDHI fungicides have only recently begun to be applied on soybean crops. These fungicides are used with low frequency and always mixed with Qol and/or DMI fungicides. Although the SDHI began to be used in soybean fields in Argentina in 2015, currently, the application of these a.i. represent approximately $3 \%-4 \%$ of the total area planted to soybean or $7 \%-8 \%$ of the total area applied with fungicides. Therefore, the Cercospora isolates found insensitive were only exposed in the field to SDHI for a couple of years. It would be unlikely that a resistance mechanism developedafter being exposed briefly to these fungicides. Therefore, we hypothesize that Cercospora species are insensitive (naturally resistant) to SDHI fungicidesin vitro because of unknown factors. Our results are in line with those reported by Nikou et al. (2009), who tested different fungicides on the in vitro mycelial growth of $C$. beticola and found that boscalid had the lowest fungitoxicity, with an average inhibition percentage of $22 \%(1.7 \%-39 \%)$ at $5 \mu \mathrm{g} / \mathrm{ml}$. Recently, Ishii et al. (2016) reported that isolates of Colletotrichum gloeosporioides, C. acutatum, C. cereale, and $\mathrm{C}$. orbiculare tested insensitive to SDHI fungicides (boscalid, fluxapyroxad, and fluopyram). In that study, authors sequenced the $s d h B, s d h C$, and $s d h D$ genes but did not find mutations associated with $\mathrm{SDHI}$ resistance. Consequently, these authors proposed that Colletotrichum species are insensitive or naturally resistant to SDHI. These results are similar to those presented here for Cercospora. Future studies such as in vitro and in vivo inhibition tests involving more Cercospora isolates and different SDHI a.i. should seek to test this hypothesis. In order to fully confirm the insensitivity of Cercospora to SDHI, it is important to establish the relationship between in vitro inhibition assays and CLB/PSS control efficacy in field trials. Secondly, to rule out that mechanisms other than point mutations could confer resistance to SDHI, genome-wide association approaches could help identify different mechanisms that could generate resistance to certain fungicides.

The C. kikuchii CYP51 protein is coded by a 1,632 bp intron-free gene with homology to other fungal cyp51 genes and is present as a single copy in the C. kikuchii genome (Sautua et al., 2019b). Polymorphisms were detected in the partial sequences of the cyp51 gene sequenced from the 36 isolates tested here, and none of the SNPs corresponded to any mutation known in Cercospora or other genera of phytopathogenic fungi that confers resistance to DMI. In the present study, the lowest average $\mathrm{EC}_{50}$ value corresponded to difenoconazole, which only began to increase in use in recent growing seasons and in mixtures with SDHI or Qol fungicides. In contrast, we have detected higher $\mathrm{EC}_{50}$ values for cyproconazole, the most commonly used DMI fungicide in the history of soybean production in Argentina, Bolivia, and Brazil (Carmona et al., 2017a). This indicates a loss of sensitivity of the Cercospora populations in Argentina towards this particular DMI molecule. Nevertheless, all isolates were sensitive to all DMI molecules tested, except for a single C. kikuchii isolate from Bolivia, which was resistant to some DMI molecules. Two new mutations were identified in the cyp51 gene for this Bolivian isolate, conferring nonsynonymous amino acid substitutions I387M and D440N. Neither of these match the mutations that correspond to previously reported amino acid polymorphisms associated with DMI resistance in C. beticola (E169, I330T, P384S, E297K; Nikou et al., 2009). However, because these mutations are solely present in the only DMI-resistant isolate, we speculate that they may be involved in the loss of sensitivity to cyproconazole, tebuconazole, and prothioconazole $\left(\mathrm{EC}_{50}\right.$ values equal to $45.8,10$, and $6 \mu \mathrm{g} / \mathrm{ml}$, respectively). Resistance could be attributed to this mutation, but future experiments and analysis should confirm this hypothesis as mechanisms other than single-site mutations in the cyp51 gene could also be involved in the DMI resistance observed in the Bolivian isolate.

Multisite fungicides have been widely used in horticulture for many years, and during the last 10 years their use has increased significantly in Brazil to control soybean rust (Phakopsora pachyrhizi; Carmona et al., 2017a). Even though the risk of developing resistance to mancozeb is considered low (Carmona et al., 2018), the appearance of several tolerant or resistant fungal species on various crops has been reported (Yang et al., 2019). We cannot confirm that the Cercospora species evaluated here should be considered resistant or naturally insensitive to mancozeb, because mancozeb has never been used on soybean for the control of any disease in Argentina.

Our findings suggest that Qol-resistance is widespread in Argentinian Cercospora populations causing CLB/PSS, as all of the populations tested appear to be composed of strobilurin-resistant individuals and the G143A mutation is present in the majority of the isolates collected from soybean and from alternative hosts such as A. hybridus and A. hortorum. Likewise, half of the tested isolates were highly resistant to carbendazim, suggesting that resistance to this fungicide is spreading in Cercospora populations as well. Moreover, this confirms that isolates of the Argentinian population of Cercospora are harbouring multiple amino acid substitutions that confer resistance to fungicides with different modes of action, which may have implications when mixes of fungicide a.i. are applied. Secondly, SDHI fungicides are a special case for which we propose that the Cercospora species evaluated here are insensitive (naturally resistant)in vitro. Similarly, mancozeb, an example of a multisite fungicide, only exhibited complete inhibition of mycelial growth at $100 \mu \mathrm{g} / \mathrm{ml}$. Consequently, it was only possible to establish the in vitro baseline sensitivity of Cercospora isolates causing CLB/PSS to five DMls and carbendazim. This is the first fungicide sensitivity study to be carried out for Cercospora species causing CLB/PSS of soybean in Argentina. Therefore, we tested several isolates and technical- and commercial-grade fungicides. The $\mathrm{EC}_{50}$ values estimated in this work represent the baseline fungicide sensitivity to DMI and carbendazim, as there are no isolates available from previous years. The results presented herein will be useful to guide detection and evaluation of sensitivity shifts in Cercospora populations towards these fungicides during subsequent years. Finally, further 
studies are needed to (a) fully elucidate the basis of different molecular mechanisms that may be involved in the resistance to Qol, MBC, and DMI fungicides; (b) confirm insensitivity or natural resistance to SDHI; and (c) confirm the lack of fungitoxicity of mancozeb in Cercospora.

\section{ACKNOWLEDGEMENTS}

This work has been financially supported by the University of Buenos Aires Project UBACyT 20020170100147BA and in part by BASF Argentina SA. Additional support was also provided, in part, by the Louisiana State Board of Regents (LEQSF-2016-19-RD-A-1). The authors thank Nova S.A. \& Agrofina S.A. for supplying the technicalgrade fungicides for the experiments.

\section{CONFLICT OF INTEREST}

The authors have no conflict of interest to declare.

\section{DATA AVAILABILITY STATEMENT}

The data that support the findings of this study (all alignments and phylogenetic trees) are openly available in Github at https://github. com/vinsondoyle/SautuaPMS2020. Accession numbers of the 438 nucleotide sequences for Cercospora spp. isolates generated in this study are available in GenBank at https://www.ncbi.nlm.nih.gov/ genbank/ with accession numbers shown in Table S2.

\section{ORCID}

Francisco J. Sautua iD https://orcid.org/0000-0003-1269-6335 Marcelo A. Carmona iD https://orcid.org/0000-0003-0247-9652

\section{REFERENCES}

Albu, S., Schneider, R.W., Price, P.P. and Doyle, V.P. (2016a) Cercospora cf. flagellaris and Cercospora cf. sigesbeckiae are associated with cercospora leaf blight and purple seed stain on soybean in North America. Phytopathology, 106, 1376-1385.

Albu, A., Price, T., Doyle, V., Padgett, B. and Schneider, R. (2016b) The G143A mutation is responsible for strobilurin fungicide resistance in Cercospora cf. flagellaris, a leaf blight and purple seed stain pathogen of Louisiana soybean. Plant Health Progress, 17, 197.

Bakhshi, M., Arzanlou, M., Babai-ahari, A., Groenewald, J.Z. and Crous, P.W. (2018) Novel primers improve species delimitation in Cercospora. IMA Fungus, 9, 299-332.

Bandara, A.Y., Weerasooriya, D.K., Bradley, C.A., Allen, T.W. and Esker, P.D. (2020) Dissecting the economic impact of soybean diseases in the United States over two decades. PLoS ONE, 15, e0231141.

Birla, K., Rivera-Varas, V., Secor, G.A., Khan, M.F.R. and Bolton, M.D. (2012) Characterization of cytochrome b from European field isolates of Cercospora beticola with quinone outside inhibitor resistance. European Journal of Plant Pathology, 134, 475-488.

Carbone, I. and Kohn, L.M. (1999) A method for designing primer sets for speciation studies in filamentous ascomycetes. Mycologia, 91, 553-556.

Carmona, M., Gally, M., Sautua, F., Abello, A. and Lopez, P. (2011) Use of azoxystrobin and triazoles mixtures to control late season diseases in soybean crop. Summa Phytopathologica, 37, 134-139.

Carmona, M., Sautua, F., Perelman, S., Gally, M. and Reis, E.M. (2015) Development and validation of a fungicide scoring system for management of late season soybean diseases in Argentina. Crop Protection, 70, 83-91.
Carmona, M., Reis, E. and Sautua, F. (2017a) Sustainable chemical control of main soybean diseases in South America. In: Fletcher, B. (Ed.) Soybeans: Cultivation, Nutritional Properties and Effects on Health. New York, USA: Nova Science Publishers Inc., pp. 203-245.

Carmona, M., Sautua, F., Scandiani, M., Bello, R., Lopez, V. and Luque, A. (2017b) In vitro sensitivity assessment for late season soybean pathogens to fungicide mixtures. Australasian Plant Disease Notes, 12, 20.

Carmona, M., Reis, E. and Sautua, F. (2018) Fungi resistance to fungicides in field crops: a growing problem worldwide. In: Rodríguez, P.P., SotoGómez, D. and de la Calle, I. (Eds.) Fungicides: Perspectives, Resistance Management and Risk. New York, USA: Nova Science Publishers Inc., pp. 149-193.

Crous, P.W., Groenewald, J.Z., Risede, J.M. and Hywel-Jones, N.L. (2004) Calonectria species and their Cylindrocladium anamorphs: species with sphaeropedunculate vesicles. Studies in Mycology, 50, 415-430.

Dellaporta, S.L., Wood, J. and Hicks, J.B. (1983) A plant DNA minipreparation: Version II. Plant Molecular Biology Reporter, 1, 19-21.

Dixon, E., Barlow, W., Walles, G., Amsden, B., Louis Hirsch, R., Pearce, R. et al. (2020) Cytochrome b mutations F129L and G143A confer resistance to azoxystrobin in Cercospora nicotianae, the frogeye leaf spot pathogen of tobacco. Plant Disease, 104, 1781-1788.

Edgar, R.C. (2004) MUSCLE: multiple sequence alignment with high accuracy and high throughput. Nucleic Acids Research, 32, 1792-1797.

Fehr, W.R. and Caviness, C.E. (1977) Stages of Soybean Development. Special Report 87. Ames, IA, USA: lowa State University.

Groenewald, J.Z., Nakashima, C., Nishikawa, J., Shin, J.H., Park, J.H., Jama, A.N. et al. (2013) Species concepts in Cercospora: Spotting the weeds among the roses. Studies in Mycology, 75, 115-170.

Imazaki, I., lizumi, H., Ishikawa, K., Sasahara, M., Yasuda, N. and Koizumi, S. (2006a) Effects of thiophanate-methyl and azoxystrobin on the composition of Cercospora kikuchii populations with thiophanate-methyl-resistant strains. Journal of General Plant Pathology, 72, 292-300.

Imazaki, I., Ishikawa, K., Yasuda, N., Miyasaka, A., Kawasaki, S. and Koizumi, S. (2006b) Incidence of thiophanate-methyl resistance in Cercospora kikuchii within a single lineage based on amplified fragment length polymorphisms in Japan. Journal of General Plant Pathology, 72, 77-84.

Ishii, H., Zhen, F., Hu, M., Li, X. and Schnabel, G. (2016) Efficacy of SDHI fungicides, including benzovindiflupyr, against Colletotrichum species. Pest Management Science, 72, 1844-1853.

Katoh, K., Rozewicki, J. and Yamada, K.D. (2019) MAFFT online service: multiple sequence alignment, interactive sequence choice and visualization. Briefings in Bioinformatics, 20, 1160-1166.

Lanfear, R., Calcott, B., Ho, S.Y. and Guindon, S. (2012) PartitionFinder: combined selection of partitioning schemes and substitution models for phylogenetic analyses. Molecular Biology and Evolution, 29, 1695-1701.

Lanfear, R., Frandsen, P.B., Wright, A.M., Senfeld, T. and Calcott, B. (2016) PartitionFinder 2: new methods for selecting partitioned models of evolution for molecular and morphological phylogenetic analyses. Molecular Biology and Evolution, 34, 772-773.

Miyamoto, T., Ishii, H., Stammler, G., Koch, A., Ogawara, T., Tomita, Y. et al. (2010) Distribution and molecular characterization of Corynespora cassiicola isolates resistant to boscalid. Plant Pathology, 59, 873-881.

Nikou, D., Malandrakis, A., Konstantakaki, M., Vontas, J., Markoglou, A. and Ziogas, B. (2009) Molecular characterization and detection of overexpressed C-14 $\alpha$-demethylase-based DMI resistance in Cercospora beticola field isolates. Pesticide Biochemistry and Physiology, 95, 18-27.

Ogle, D.H., Wheeler, P. and Dinno, A. (2019) FSA: fisheries stock analysis. R package version 0.8.24. Available at: https://github.com/droglenc/ FSA [Accessed 2 February 2020] 
Price, P.P., Purvis, M.A., Cai, G., Padgett, G.B., Robertson, C.L., Schneider R.W. et al. (2015) Fungicide resistance in Cercospora kikuchii, a soybean pathogen. Plant Disease, 99, 1596-1603.

R Core Team. (2020) R: A Language and Environment for Statistical Computing. Vienna, Austria: R Foundation for Statistical Computing. Available at: http://www.R-project.org [Accessed 2 February 2020]

Ritz, C., Baty, F., Streibig, J.C. and Gerhard, D. (2015) Dose-response analysis using R. PLoS ONE, 10, e0146021.

Ronquist, F., Teslenko, M., Van Der Mark, P., Ayres, D.L., Darling, A., Höhna, S. et al. (2012) MrBayes 3.2: efficient Bayesian phylogenetic inference and model choice across a large model space. Systematic Biology, 61, 539-542.

Sautua, F.J., Searight, J., Doyle, V.P., Price, P.P. III, Scandiani, M.M. and Carmona, M.A. (2019a) The G143A mutation confers azoxystrobin resistance to soybean cercospora leaf blight in Bolivia. Plant Health Progress, 20, 2-3.

Sautua, S., Gonzalez, S., Doyle, V., Berretta, M., Gordó, M., Scandiani, M. et al. (2019b) Draft genome sequence data of Cercospora kikuchii, a causal agent of cercospora leaf blight and purple seed stain of soybeans. Data in Brief, 27, 104693.

Sautua, F.J., Searight, J., Doyle, V.P., Scandiani, M.M. and Carmona, M.A. (2020) Cercospora cf. nicotianae is a causal agent of cercospora leaf blight of soybean. European Journal of Plant Pathology, 156, $1227-1231$

Sierotzki, H. (2015) Respiration inhibitors: complex III. In: Ishii, H. and Hollomon, D.W. (Eds.) Fungicide Resistance in Plant Pathogens. Tokyo: Springer, pp. 119-143.

Sierotzki, H. and Scalliet, G. (2013) A review of current knowledge of resistance aspects for the next-generation succinate dehydrogenase inhibitor fungicides. Phytopathology, 103, 880-887.

Soares, A.P.G., Guillin, E.A., Borges, L.L., Silva, ACTd, Almeida, ÁMRd, Grijalba, P.E. et al. (2015) More Cercospora species infect soybeans across the Americas than meets the eye. PLoS ONE, 10, e0133495.

Stamatakis, A. (2014) RAxML Version 8: A tool for phylogenetic analysis and post-analysis of large phylogenies. Bioinformatics, 30, 1312-1313.

Sukumaran, J. and Holder, M.T. (2010) DendroPy: a Python library for phylogenetic computing. Bioinformatics, 26, 1569-1571.
U.S. Food and Drug Administration. (2001) Bacteriological Analytical Manual, online. Gaithersburg, MD: AOAC International. Available at: https://www.fda.gov/food/laboratory-methods-food/bacteriolo gical-analytical-manual-bam [Accessed 20 May 2020]

Untergasser, A., Cutcutache, I., Koressaar, T., Ye, J., Faircloth, B.C., Remm, M. et al. (2012) Primer3-new capabilities and interfaces. Nucleic Acids Research, 40, 7e115.

Vielba-Fernández, A., Bellón-Gómez, D., Torés, J.A., de Vicente, A., Pérez-García, A. and Fernández-Ortuño, D. (2018) Heteroplasmy for the cytochrome $b$ gene in Podosphaera xanthii and its role in resistance to Qol fungicides in Spain. Plant Disease, 102, 1599-1605.

Ward, N.A., Schneider, R.W., Chanda, A., Silva, E.C., Price, P.P. and Cai, G. (2015) Cercospora leaf blight and purple seed stain. In: Hartman, G.L., Rupe, J.C., Sikora, E.J., Domier, L.L., Davis, J.A. and Steffey, K.L. (Eds.) Compendium of Soybean Diseases and Pests. St Paul, MN, USA: APS Press, pp. 37-41.

Yang, L., He, M., Ouyang, H., Zhu, W., Pan, Z.C., Sui, Q.J. et al. (2019) Cross-resistance of the pathogenic fungus Alternaria alternata to fungicides with different modes of action. BMC Microbiology, 19, 205.

Ziogas, B.N., Baldwin, B.C. and Young, J.E. (1997) Alternative respiration: a biochemical mechanism of resistance to azoxystrobin (IClA 5504) in Septoria tritici. Pesticide Science, 50, 28-34.

\section{SUPPORTING INFORMATION}

Additional supporting information may be found online in the Supporting Information section.

How to cite this article: Sautua FJ, Doyle VP, Price PP, et al. Fungicide resistance in Cercospora species causing cercospora leaf blight and purple seed stain of soybean in Argentina. Plant Pathol. 2020;69:1678-1694. https://doi.org/10.1111/ ppa.13261 